\title{
3D Fine-scale Terrain Variables from Underwater Photogrammetry: A New Approach to Benthic Microhabitat Modeling in a Circalittoral Rocky Shelf
}

\author{
Elena Prado ${ }^{1, *(1)}$, Augusto Rodríguez-Basalo ${ }^{1}\left(\mathbb{D}\right.$, Adolfo Cobo $^{2,3}$, Pilar Ríos ${ }^{1}$ \\ and Francisco Sánchez ${ }^{1}$ \\ 1 Instituto Español de Oceanografía (IEO), Centro Oceanográfico de Santander, Promontorio San Martin s/n, \\ 39004 Santander, Spain; augusto.rodriguez@ieo.es (A.R.-B.); pilar.rios@ieo.es (P.R.); \\ francisco.sanchez@ieo.es (F.S.) \\ 2 Photonics Engineering Group, Universidad de Cantabria, Plaza de la Ciencia, Avenida Los Castros, s/n, \\ 39005 Santander, Spain; adolfo.cobo@unican.es \\ 3 CIBER-BBN, Instituto de Salud Carlos III, Instituto de Investigacion Sanitaria Valdecilla (IDIVAL), \\ Calle Cardenal Herrera Oria s/n, 39011 Santander, Spain \\ * Correspondence: elena.prado@ieo.es
}

Received: 11 June 2020; Accepted: 26 July 2020; Published: 31 July 2020

\begin{abstract}
The relationship between 3D terrain complexity and fine-scale localization and distribution of species is poorly understood. Here we present a very fine-scale 3D reconstruction model of three zones of circalittoral rocky shelf in the Bay of Biscay. Detailed terrain variables are extracted from 3D models using a structure-from-motion (SfM) approach applied to ROTV images. Significant terrain variables that explain species location were selected using general additive models (GAMs) and micro-distribution of the species were predicted. Two models combining BPI, curvature and rugosity can explain 55\% and 77\% of the Ophiuroidea and Crinoidea distribution, respectively. The third model contributes to explaining the terrain variables that induce the localization of Dendrophyllia cornigera. GAM univariate models detect the terrain variables for each structural species in this third zone (Artemisina transiens, D. cornigera and Phakellia ventilabrum). To avoid the time-consuming task of manual annotation of presence, a deep-learning algorithm (YOLO v4) is proposed. This approach achieves very high reliability and low uncertainty in automatic object detection, identification and location. These new advances applied to underwater imagery (SfM and deep-learning) can resolve the very-high resolution information needed for predictive microhabitat modeling in a very complex zone.
\end{abstract}

Keywords: circalittoral rocky shelf; underwater 3D photogrammetry; structure-from-motion; Avilés Canyon System; benthic habitat modeling; deep-learning; YOLO; annotation of underwater images

\section{Introduction}

Circalittoral rock substrates are characterized by very diffuse light and more constant hydrodynamic conditions than in the upper beds, although the currents in some places can be strong. The depth at which the circalittoral zone begins is directly dependent on the intensity of light reaching the seabed. Most of the circalittoral rock bottoms are dominated by animal species, because of the weakness of the light. The number of species characterizing these seafloors can be very high, depending on the different geographic areas, the geomorphology of the bottom and different factors that affect them [1].

In the rocky circalittoral environment of the Bay of Biscay there is a great variety of species, often of small size. The most abundant species were: Ophiothrix fragilis, Leptometra celtica, Phakellia ventilabrum, Dendrophyllia cornigera and Gracilechinus acutus [2]. The cup sponge (P. ventilabrum) and the yellow 
coral (D. cornigera) are the most representative structural species in the vulnerable habitat 1170 of the EU Directive [1] within the studied area. As for microscale, the Artemisina transiens sponge appears in abundance [3]. In this area the sponge communities make up 14.5\% of coverage [4]. This variety of species in the same geographic location makes the area complex to map. It is even more difficult to carry out predictive habitat modeling studies because very detailed scales must be established.

Predictive habitat models were used widely in recent years to statistically infer the distribution of benthic species of interest in ocean bottoms, especially oriented to protected zone management [5-7] and marine strategy framework directive (MSFD) implementation [8,9]. Therefore, statistical models have become a key tool for any marine space management [10-12] enabling better understanding of the spatial distribution of the habitats of the seabed and also showing the relationships between the species and their environment. Habitat maps also help managers to design environmental measures for specific vulnerable habitats in the establishment and management of marine reserves. These models feed primarily on data acquired by Multibeam Echosounders (MBEs) and other acoustic techniques [13]. The spatial resolution of bathymetric data often determines the maximum working scale of predictive habitat modeling. The use of a regional approach with tens of meters of resolution per pixel [14] or global scale, with hundreds of meters of resolution per pixel [15] is common.

Spatial scale or spatial resolution is one of the most critical aspects in habitat mapping, as well as one of the most misunderstood [16]. A microhabitat ranges in size from centimeters to one meter [17]; so individual biogenic structures such as corals and sponges could be included in this potential marine benthic habitat type. However, in deep-sea conditions, beyond diving range, it is very difficult to obtain descriptive variables of the seafloor and locations of species that describe microhabitat characteristics with very-high resolution.

At depths greater than $100 \mathrm{~m}$, it is very difficult to include in marine predictive model variables that take into account the structural complexity of the habitats. Habitat structural complexity is a key factor in ecology [18] and it is often positively linked to biodiversity in marine environments [19,20]. Seafloor topography is a good approximation to define this habitat structural complexity. Topography has a relevant role in current regulation, interaction of flow and sediment and access to food and other chemical components. Habitat structural complexity may have an important effect on ecological interactions and its inclusion can improve the precision and accuracy of ecological assessments [21]. Therefore, where marine areas vary in structural complexity, it is important to quantify this variability, which is in turn influenced by the working scale. For example, a total of 3037 macrofaunal specimens were collected from canals and cavities of the 15 sponges examined in Mediterranean marine caves [22] and, in tidal flats and flood plains, elevation changes in the order of centimeters can determine species distribution, interaction and ecosystem services [23].

Structure from motion (SfM), a form of 3D photogrammetry, is an emerging approach in underwater marine imaging research. Using SfM, scientists can derive complete 3D models of ocean floor surface. Using massive correlation points, SfM techniques can achieve very-high resolution definition of the surface. Therefore, thanks to the use of this approach, advanced progress is being made in knowledge about biologic characteristics of many benthic marine organisms that were poorly understood. Based on underwater 3D photogrammetry, a very detailed population structure of Paramuricea clavata [24] and Placogorgia sp. [25,26] has been identified in deep-sea gorgonian forest. In a similar way, growth rates of Paragorgia arborea and Primnoa resedaeformis [27] and approximate age of 16 sponge species in the Caribbean Sea [28] have been obtained from nondestructive in situ methods. The capacity to describe the morphometry of a surface in a very-high resolution mode demonstrates its application to evaluate coral reef rugosity [29,30] or coral reef structural complexity [31,32]. Factors such as species richness, epifauna abundance and fish abundance increase with structural complexity [33]. Although the structural complexity indices usually applied (i.e., Rugosity index) provide a reasonably reliable assessment of the structural complexity, the ecological implications still remain unclear [34]. 
Predictive habitat models were used to determine which derived terrain variables were most useful in explaining observed spatial patterns. These terrain variables were obtained from SfM [35,36]; but the application of this methodology to benthic microhabitat mapping in deep waters is still scarce.

Predictive habitat models need to have high presence of examples in the study area to predict with high reliability the distribution of the habitats under study [37-39]. Nowadays, experts perform highly repetitive tasks of manual image annotation which becomes the bottleneck in mapping studies. The large amount of information to analyze; a single ROV survey can generate tens of hours of video or thousands of photographs; makes the annotation process one of the most time-consuming tasks. Usually, less than $2 \%$ of the acquired imagery ends up being manually annotated by a marine expert, resulting in a significant loss of information [40]. To perform this work automatically and unsupervised, recent deep-learning algorithms for automatic object detection or semantic segmentation of images seem the most appropriate solution [41]. This object detection networks are able to identify and classify multiples specimens in a given image, predicting rectangular bounding boxes around them with their location. Semantic segmentation, on the other hand, provides a classification of every pixel in the image, thus identifying specimens with their precise shape. For our study, which aims to automatically classify, count and place every specimen, the object detection approach seems the most efficient.

Their application for the analysis of images of benthic species has hardly been explored by the scientific community, with very few references of its use and application in the marine environment [42]. Existing studies have focused mainly on coral reefs, where achieving coral coverage is one of the main issues. Different algorithms were proposed: a custom multiscale convolutional network [43], texture features extracting and self-organizing maps [44], support vector machines [45] or, more recently, semantic segmentation models [46]. Recent works also benefit from 3D modeling techniques of ocean floors to improve performance, using for example a ResNet152 classifier [47] or even ensembles of several concurrent algorithms [48].

The continental shelf is under great anthropic pressure, mainly due to its proximity to the coast and its bathymetric distribution with moderate depths. Both in sedimentary and rocky bottoms, fishing activities have negative effects on the benthic communities, but, on the other hand fishing activity has a socioeconomic value. In this area, there are some fisheries, so it is important to establish the vulnerable habitats' spatial distribution in order to identify potential conflicts of use [49]. Consequently, the management of activities in these areas should be done based on the detailed characterization of their habitats.

Currently, the link between 3D terrain complexity and geographic localization and distribution of species of vulnerable habitats is poorly understood. Here, we present a very fine-scale 3D reconstruction model of a circalittoral rock area of a portion of the Bay of Biscay continental shelf. The study area is within the Avilés Canyon System (ACS), declared a site of community importance (SCI). The aims of this study are: (1) characterization of some habitats of the Avilés circalittoral rocky zone using 3D high resolution modeling, (2) extraction of terrain variables from a 3D model of the circalittoral rocky zone to determine the principal factors explaining species location, (3) prediction of the detailed distribution of the selected species based on imagery using predictive habitat modeling and (4) testing of a new methodology of automatic species localization in images (records of presence) based on deep-learning algorithms.

\section{Materials and Methods}

\subsection{Study Area}

The area of the Bay of Biscay continental shelf located in the headwaters of the Avilés Canyon System (ACS) is characterized by rocky outcrops (Figure 1). This is mainly due to the sedimentary transport mechanisms associated with the ACS's oceanographic dynamics. Throughout the entire Bay of Biscay, the continental shelf is generally narrow; a typical characteristic feature of compressive continental margins [50]. Its width varies from $12 \mathrm{~km}$, at the head of the Avilés Canyon (AC), to $40 \mathrm{~km}$, 
with maximum depths of about $200 \mathrm{~m}$ and exceptionally as high as $300 \mathrm{~m}$ east of the AC. The slope varies gently, ranging from 0 to less than $1^{\circ}$. The area is highly affected by tectonic action, with interference of various strain directions [51]. This strong tectonic influence results in a very irregular continental shelf edge, with incoming and outgoing directions oblique to the coastline. In general, the existence of strong currents in the Bay of Biscay continental shelf prevents the accumulation of large sedimentary deposits on this rocky area. The materials are dragged and channeled through the canyons, resulting in a platform with low sedimentary thickness.

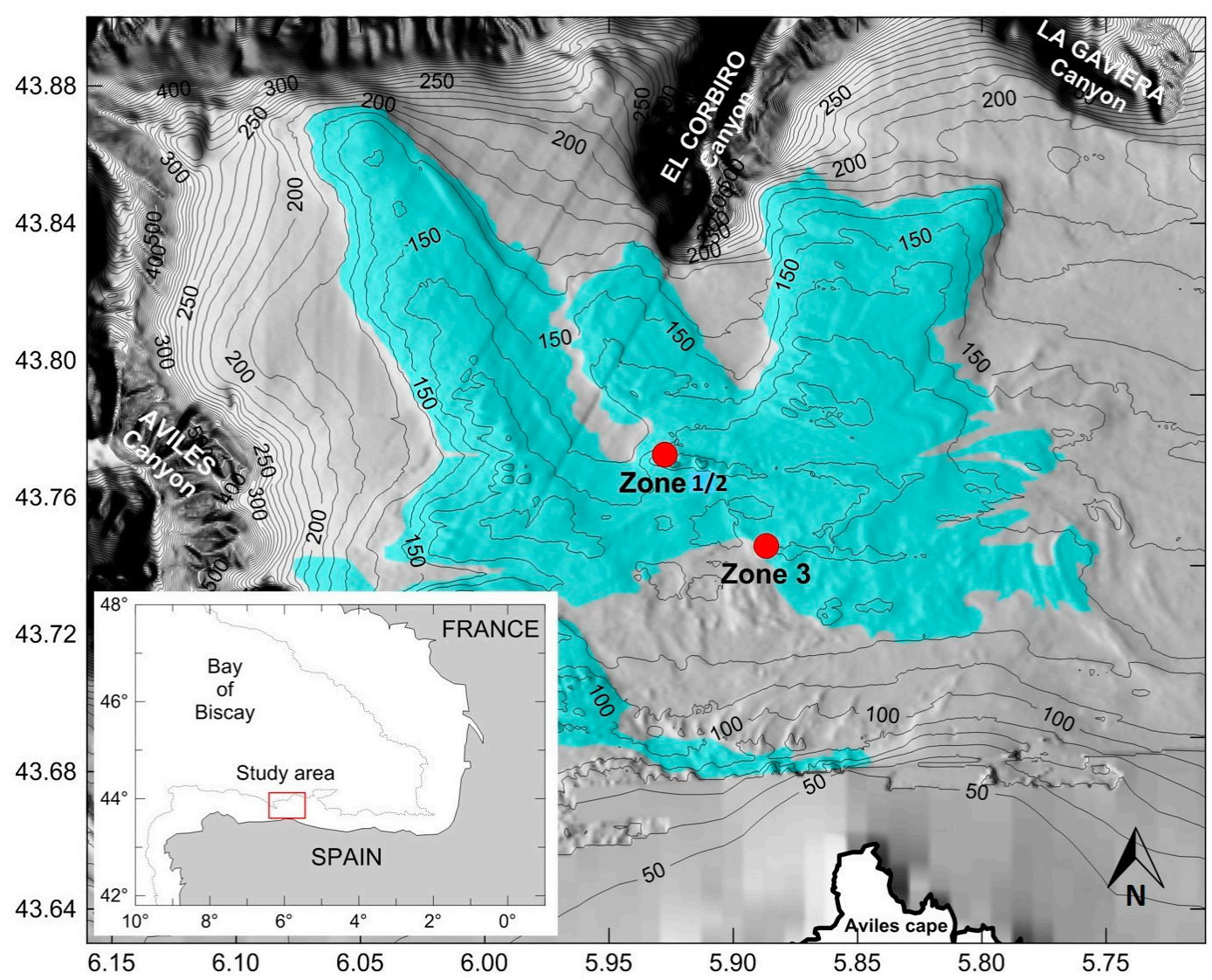

Figure 1. General situation and study area maps with rocky bottoms (in blue) and test zones. Detail of locations of the stations in the study shown on a bathymetric map of the area ( $32 \mathrm{~m} / \mathrm{pixel})$.

This area is currently declared a site of community importance (SCI) in the context of the Natura 2000 network, mainly due to the existence of coral reefs [52].

\subsection{Survey Description and Image Acquisition}

Images were obtained from 3 test zones (Figure 1) in two different trips, each associated with the following projects; Zone 1 and Zone 2: ECOMARG 2017, monitoring of the marine protected area of El Cachucho and Zone 3: LIFE IP INTEMARES, Action A4, Diagnosis of the impact of human activities and climate change on marine RN 2000 and proposals to control, eliminate or mitigate its effects.

The images analyzed in this study were obtained using the remotely operated towed vehicle (ROTV) Politolana (Figure 2). The ROTV Politolana, designed by the Santander Oceanographic Center of the Spanish Institute of Oceanography (IEO), is a robust submarine towed vehicle designed to study the deep-sea floor using photogrammetric methods [53]. The vehicle can be operated down to a maximum of 2000-m depth. In this case, transects were carried out navigating at a 0.8-1.0 knots at 2-4 m over the sea floor. The vehicle has bidirectional telemetry to control the submerged instruments (altimeter, CTD probe, compass, video and still camera control) and sends data to the surface control 
unit in real time. This vehicle acquires both still pictures and HD videos simultaneously, synchronizing them with measurements of the existing environmental conditions.

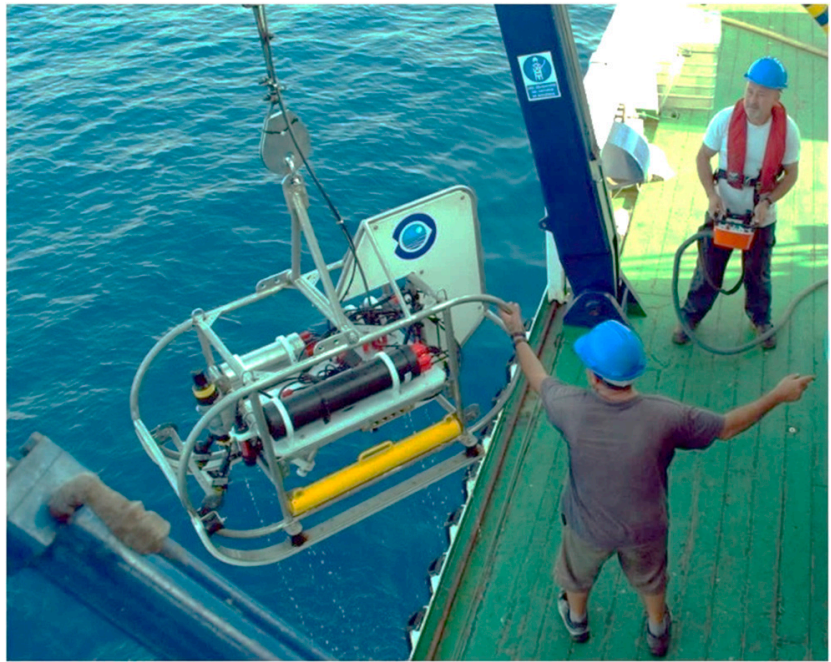

(a)

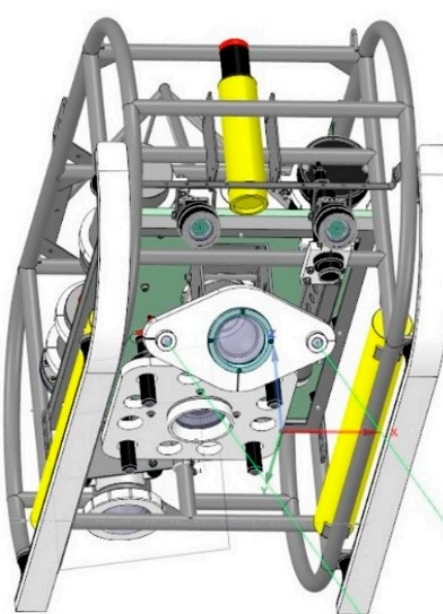

(b)

Figure 2. Remotely operated towed vehicle (ROTV) Politolana photogrammetric vehicle. (a) Maneuver for deploying the vehicle before an image transect survey; (b) sketch of the lower side showing the layout of cameras, lights and laser pointers.

Absolute positioning of the vehicle is provided by a Kongsberg HiPAP 502 super-(ultra)-short base line (SSBL). This fully omni directional system can be pointed in any direction below the vessel, as the transducer has the shape of a sphere and an operating area of $200^{\circ}$. The ROTV is positioned by an acoustically operated transponder. Ad hoc designed software performs synchronization of data in real time. ocean floor observation protocol-OFOP software [54] processes the observation files subsequently and merges them with additional sensor data, which are corrected for space and time offsets and finally splined producing a complete data set for each individual deployment.

Video transects of Zone 1 and Zone 2, were recorded in July 2017 during the ECOMARG-2017 survey (E0717_TV02); at a range of depths around $125 \mathrm{~m}$. The video-camera used was a Full HD video camera (Sony HD-700-CX), at $45^{\circ}$ with respect to the seabed and two LED lights $\left(12,600\right.$ lumens $/ 6000^{\circ}$ Kelvin) were attached to the image system. The system was equipped with 2 parallel laser beams separated by a constant distance of $20 \mathrm{~cm}$ (Figure $2 \mathrm{~b}$ ). This distance provides a method to scale and validate the geometric uncertainty of the resulting model. The two sections of video transect analyzed in this study were about $100 \mathrm{~m}$ and $50 \mathrm{~m}$ long for Zone 1 and Zone 2, respectively. The footprint on the seabed was around $3 \mathrm{~m}$ wide; this imaging swath varies depending on the height of flight over the seabed and its topography.

High resolution photographs used for Zone 3 were acquired during the INTEMARES A4 Avilés 2018 survey (IA418_TF27); in a range of depths about $120 \mathrm{~m}$. The ROTV Politolana is fitted with a Sony Alfa 7 camera (24 megapixels) with two LED lights, at zenithal position. The system was equipped with 4 parallel laser beams separated by a constant distance of $25 \mathrm{~cm}$ that provides a method to scale the images (Figure $2 b$ ). The equipment takes pictures with a time-lapse of $0.5 \mathrm{~s}$ obtaining representative data of the habitat and benthic communities to be characterized and a collection of highly overlapping images that register a complete image of the sea floor.

\subsection{D Image Reconstruction and Digital Surface Model}

Video sections were decomposed into thousands of geopositioned overlapping images. These video frames and photographs were processed using photogrammetric Pix4D MapperPro 
software (Pix4D SA, Switzerland). This software carries out advanced automatic triangulation based purely on image content and an optimization technique [55]. The triangulation algorithm is based on binary local key points, searching for matching points by analyzing all images. Those matching points, as well as approximate values of image position and orientation provided by the Politolana telemetry system, are used in a bundle adjustment to reconstruct the exact position and orientation of the camera for every acquired image. For this study, the focal length, principal point and radial/tangential distortions of the cameras were set as initial theoretical values, while the final internal and exterior orientation parameters were determined by bundle adjustment processing.

The distance between parallel laser beams $(20 \mathrm{~cm}$ apart in video frames and $25 \mathrm{~cm}$ apart in photographs) is used as reference scale. Several scale constraints are used to fine rescale and optimize the project. With this complete automated integration of tie point measurements, camera calibration, position data given by the cameras and scale constraints, the software provides 3D dense point clouds (Figure 3a), orthomosaics (Figure 3b,d) and digital surface models (DSM) (Figure 3c,e). The products derived from the sea floor morphology, such as maps of slope, aspect, rugosity, curvature, etc. can be extracted from the DSM in a simple way. Since all the information is geo-referenced in a cartographic system (UTM-WGS84), all geographic layers obtained can be included in a GIS environment.

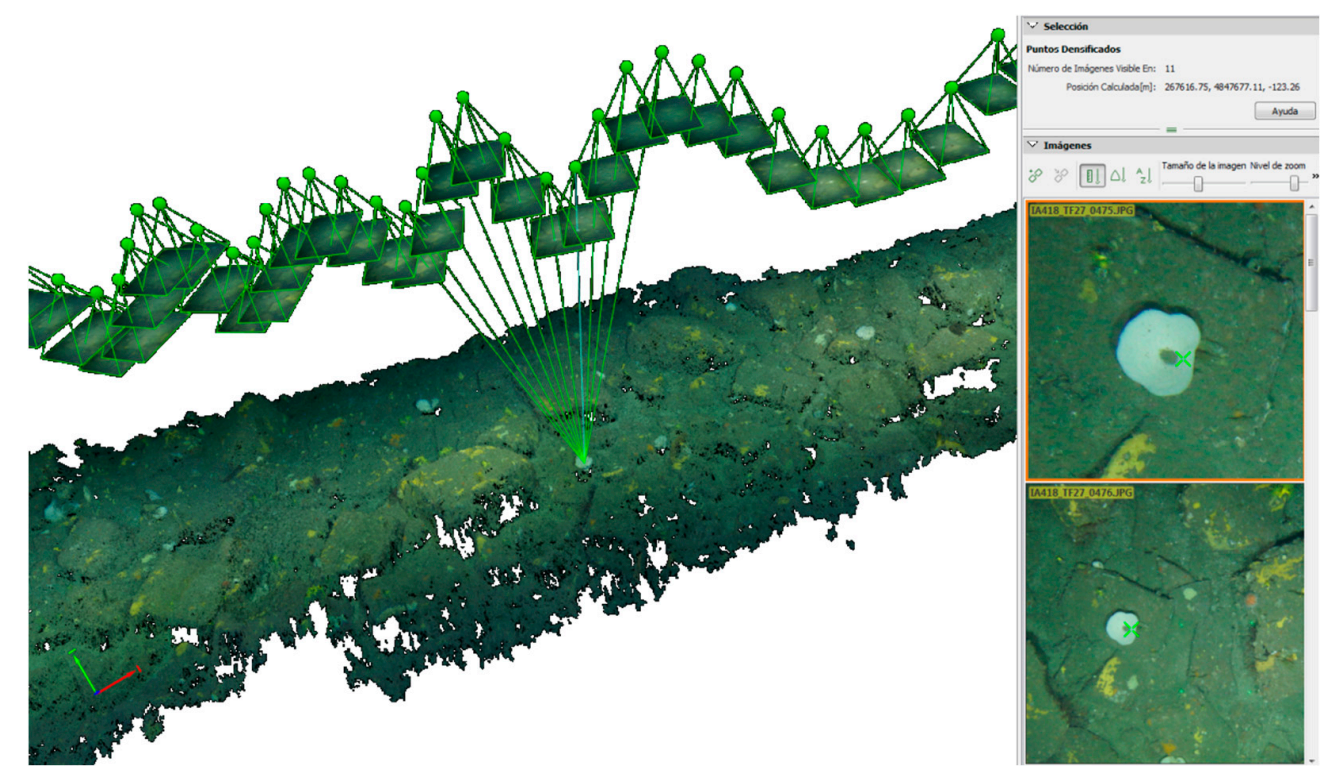

(a)

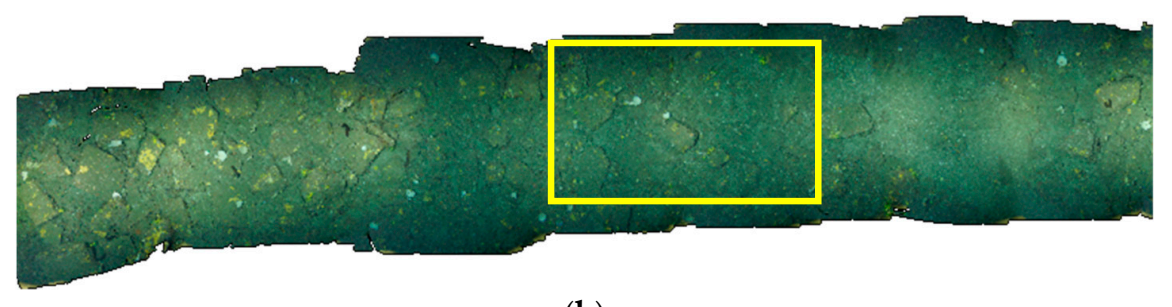

(b)

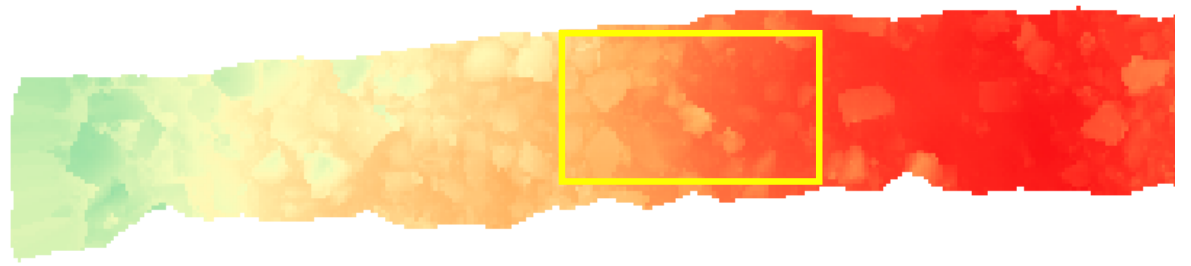

(c)

Figure 3. Cont. 


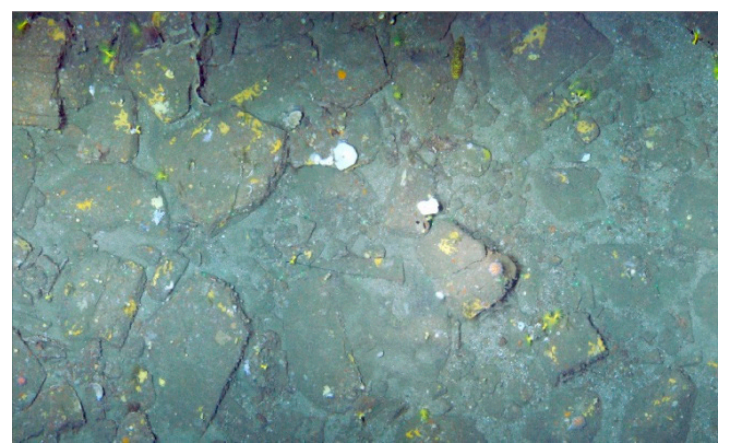

(d)

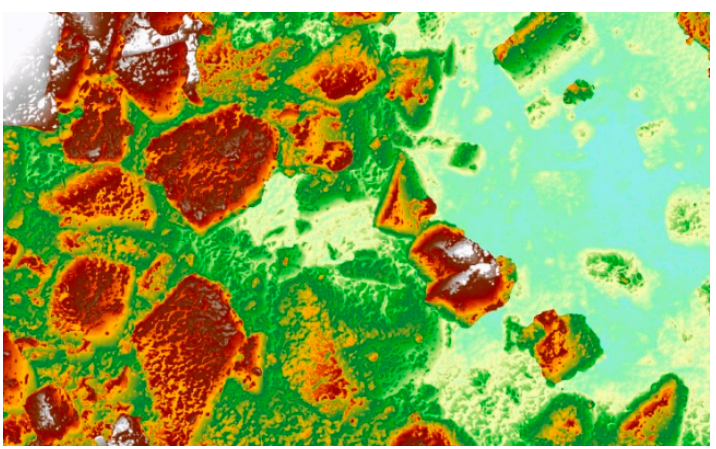

(e)

Figure 3. (a) Detail of 3D dense point cloud and thumbnails of alignment images in the Pix4D processing of Zone 3; on the right, still frames corresponding to the point selected in the 3D model; (b) portion of high resolution orthomosaic and (c) digital surface model (DSM) of the same zone; (d) and (e) zooms of orthomosaic and DSM, respectively.

The 3D point cloud is a cartographic product that contains coordinates (XYZ) of the points and color information, enabling subsequent morphometric analysis. The point cloud processing is used to extract DSM. The maximum spatial resolution ground sampling distance (GSD) was used to produce orthomosaics. These very-high resolution orthomosaics are used to annotate species presence location. To generate a DSM model, the resolution was resampled to avoid the size of the individual specimens contributing to differences in DSM.

\subsection{Terrain Analysis}

Spatial terrain properties describe the complexity of the habitat and condition the location of the specimens on the seabed. To quantify these spatial properties, DSMs of the surveyed sites were exported from Pix4D software into R.

Then, this bathymetric layer was used to calculate the terrain descriptors in R software; aspect, slope, roughness, curvature and bathymetric position index (BPI) of the terrain model (Figure 4). Aspect indicates the direction that slopes are facing, the direction of the surface expressed in two components (north and east). Slope is the vertical gradient of a surface, expressed in degrees. Terrain-surface roughness is a morphometric measure expressing how heterogeneous a surface is. Roughness is the difference between the minimum and maximum bathymetry values for a given surface area. Curvature in marine environment expresses the acceleration, deceleration, convergence and divergence of flow across a surface and therefore indicates areas influenced by erosion or deposition processes. Finally, BPI is the difference in bathymetry between a central cell and the mean value of a given group of surrounding cells.

These morphometric terrain descriptors were generated from a resampled low resolution DSM. This operation means that presence of the specimens does not contribute to generating differences in the results.

\subsection{Faunal Presences}

The target species for this study were those that, due to their size or morphologic characteristics, are easily identified in the images. Specifically: one cnidarian (Dendrophyllia cornigera (Lamarck 1816)), two sponge morphotypes (Artemisina transiens (Topsent, 1890) and Phakellia ventilabrum (Linnaeus, 1767)), three brittle stars (Ophiothrix fragilis (Abildgaard in O.F. Müller, 1789), Ophiothrix sp. III (sensu Taboada \& Perez-Portela, 2016) and Ophiura ophiura (Linnaeus, 1758) and one feather star (Leptometra celtica (M'Andrew \& Barrett, 1857)). 


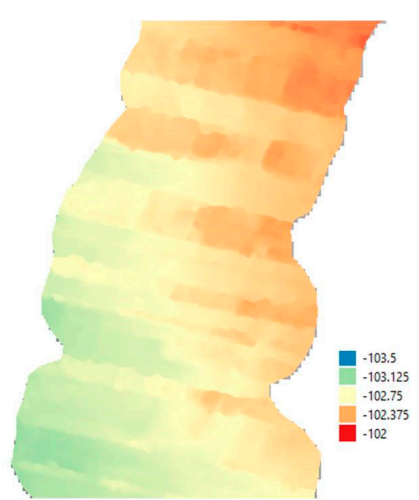

(a)

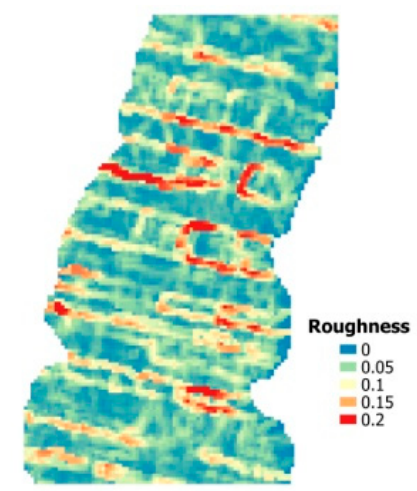

(d)

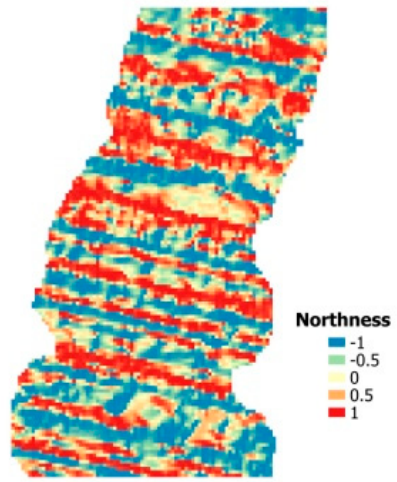

(b)

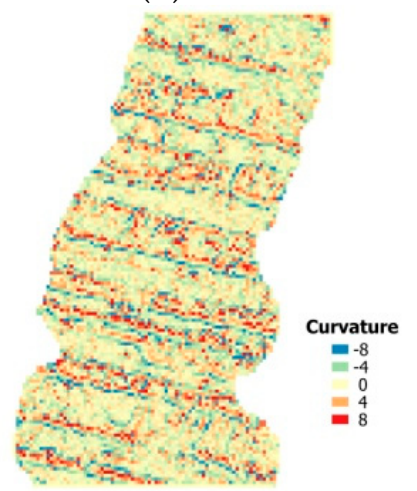

(e)

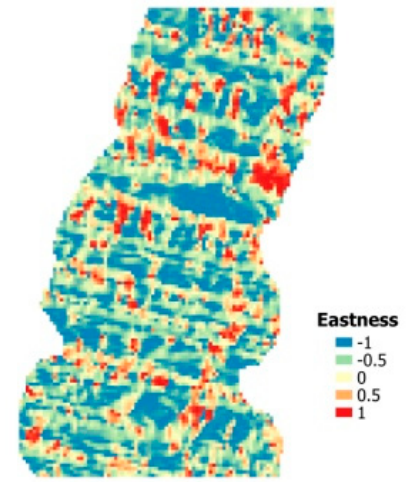

(c)

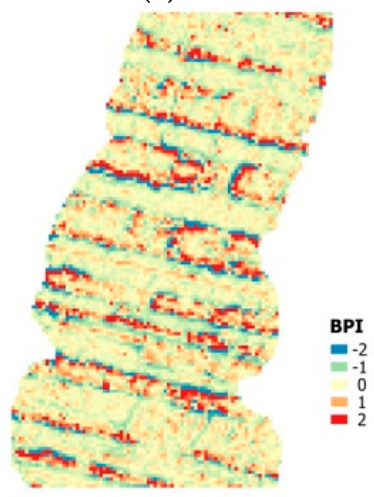

(f)

Figure 4. Zooms as examples of the topographic descriptor layer generated in this study for Zone 1. (a) Bathymetry (b) aspect (North); (c) aspect (East); (d) roughness; (e) curvature; (f) bathymetric position index (BPI).

The yellow scleractinian coral D. cornigera (Figure 5a), is well known from Ireland to the Cape Verde Islands, including in the Azores archipelago and the Mediterranean Sea, with a bathymetric distribution ranging from 80 to $600 \mathrm{~m}$. It is widely distributed in the whole Bay of Biscay and nearby areas.

P. ventilabrum (Figure $5 b$ ) is a species that is characteristic of the sponge communities on deep circalittoral rock (EUNIS habitat code A4.12), among others. It is a Demospongiae sponge with a funnel shape or flabelliform, whitish color and a wide distribution in the North Atlantic Ocean, Arctic and Mediterranean Sea; it is found at depths of 10-1863 m.

A. transiens (Figure 5c) is a globular pedunculated sponge with several slightly raised apical oscules with a main body with a spherical to elliptical shape. It is found from 35 to $126 \mathrm{~m}$ in depth and the density of these sponge grounds can reach up to $50-60 \mathrm{ind} / \mathrm{m}^{2}$, with the appearance of 'mushroom fields' (Ríos et al. 2018).

O. fragilis (Figure $5 \mathrm{~d}$ ) is a species characteristic of echinoderms and crustose communities on circalittoral rock (EUNIS habitat code A4.21). With a wide range of colors, the specimens from ACS are green, brown and/or orange alive. The color of specimens of Ophiothrix sp. III (Figure 5d) (Taboada \& Perez-Portela, 2016) from ACS is principally orange alive, but the disc is pale pink and white. O. ophiura (Figure $5 \mathrm{~d}$ ) is a species characteristic of the fine circalittoral sand Habitat (EUNIS habitat code A5.25). The color of specimens from ACS is pink. This species lives from intertidal down to more than $200 \mathrm{~m}$, on sand or muddy sand. In ACS, it lives up to a maximum depth of $240 \mathrm{~m}$, in patches of fine sand. 
L. celtica (Figure 5e) is an unstacked crinoid distributed in northeast waters of the Atlantic Ocean, West and South Africa and Mediterranean Sea. The ability of these echinoderms to adapt to different types of habitats and depths makes this species extraordinarily abundant in the Bay of Biscay Canyons, where it can colonize rocky bottoms from the circalittoral floor, at $80 \mathrm{~m}$, down to more than $1000 \mathrm{~m}$ in submarine canyons and even over coral reefs in regressive state [52].

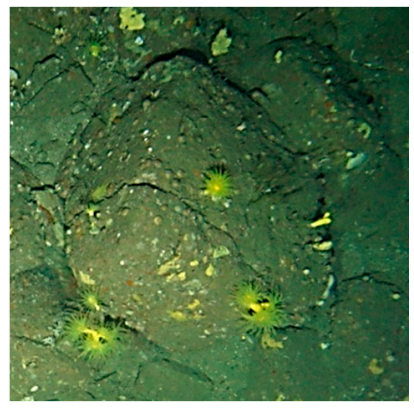

(a)

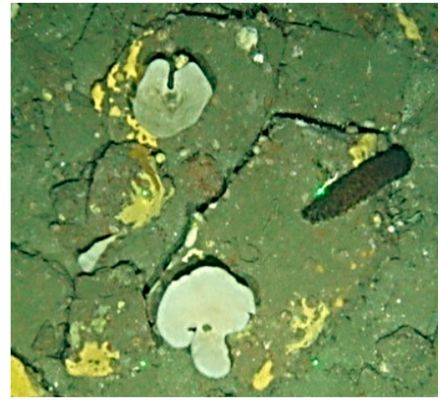

(b)

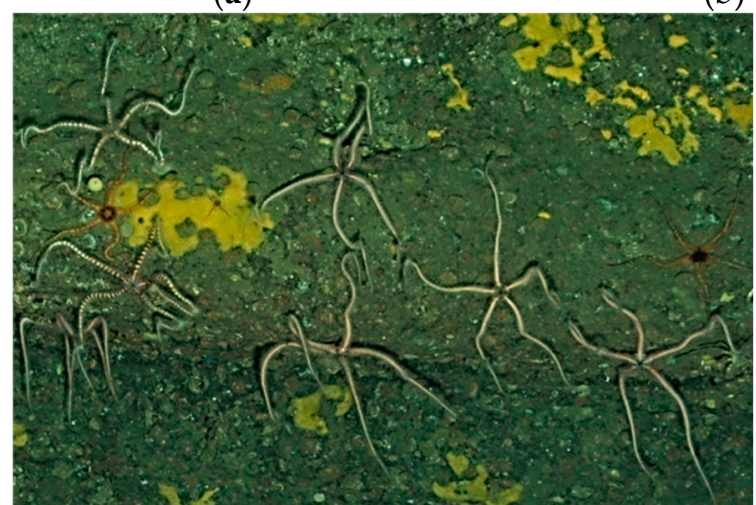

(d)

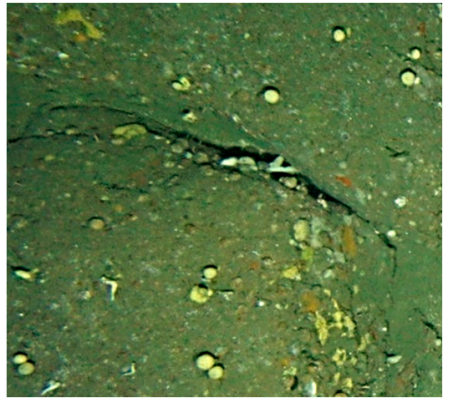

(c)

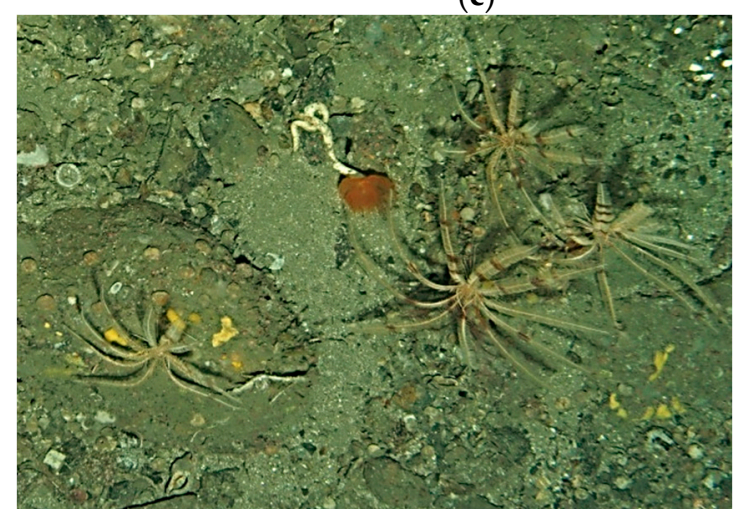

(e)

Figure 5. Selected species for the study, representative of circalittoral Avilés Canyon System (ACS) rocky bottoms habitats. (a) Dendrophyllia cornigera; (b) Phakellia ventilabrum; (c) Artemisina transiens; (d) Ophiothrix fragilis, Ophiothrix sp. III and Ophiura ophiura; (e) Leptometra celtica.

These species are annotated in the three zones on a portion of high-resolution orthomosaics generated from 3D reconstruction. In addition, for the 3 zones and for all the selected species, absences were generated manually to improve the estimation of the predictive statistical models.

To analyze the spatial pattern distributions of these species within the areas, multi-distance spatial cluster analysis is used. This approach is based on Ripley's K function [56]. A distinguishing feature of this method is that it summarizes spatial dependence (feature clustering or feature dispersion) over a range of distances. Therefore, the selection of an appropriate scale of analysis is necessary. This analysis enables the determination of whether the phenomenon of interest (e.g., positions of specimens) appears to be dispersed, clustered or randomly distributed throughout the study area using very high-resolution information $(\sim \mathrm{cm})$.

\subsection{Significant Terrain Variables and Habitat Suitability Model}

The habitat suitability model technique was applied to create maps for each target species, showing spatial distributions according to probability values. Generalized additive models (GAMs) are widely used statistical models of species distribution in habitat and environmental management modeling as they enable the incorporation of nonlinearity.

GAMs were used to determine which high-resolution-derived terrain variables were most useful in explaining observed spatial patterns and habitat distribution of the selected species. The environmental variables used were extracted from high-resolution 3D point clouds. First, to detect multicolinearity 
among the different predictors, a variance inflation factor (VIF) was established and the correlated variables discarded so inflation due to colinearity could be avoided. Second, univariate GAMs were applied to select the variables that have great influence on the presence of specimens. Third, the variance and the level of significance $(p$-value $<0.05)$ were used to select the variables that have influence on the final predictive model. Finally, once the significant variables were selected, we could combine these environmental variables derived exclusively from the terrain descriptors to obtain the most significant predictors that will help to explain the location of the species at the centimetric level.

After the models were defined, a similar GAM approach was used to predict relative abundance of selected species throughout three test zones, based on the defined models, estimation of presence and absence located in a portion of orthomosaic and the micro-bathymetric conditions.

Validation of predictive models was achieved using AUC (area under curve) tests for the presence/absence that assess misclassification rate. AUC measures the ability of model predictions to discriminate between observed presence and absence for a test dataset. It is independent of the threshold and takes into account the sensitivity (true positives), as well as specificity (false negatives).

\subsection{First Approximation of Automatic Image Annotation of Species Using Deep-Learning}

A deep learning-based algorithm was tested for the automatic annotation of specimens in the very high-resolution orthomosaic created for Zone 3. As both species identification and location is needed, an "object detection" variant of a convolutional neural network (CNN) was chosen. YOLO v4 (You Only Look Once, version 4) architecture [57] was used. It is based on a CSPDarknet53 backbone image prediction CNN network and a YOLO v3 head to predict the size and location of the object's bounding boxes. This particular approach embraces several recent improvements in the architecture and training pipeline of deep-learning algorithms that result in very good precision and fast inference times.

For the training, a network previously trained on the MS COCO dataset (80 classes of common objects) was chosen as the starting point. The supervised procedure uses a dataset of 65 high-resolution images (both full HD video frames and 24Mpx photographs) from several circalittoral rocky floors. The images were manually annotated by an expert using the web service Supervisely (http://supervise. 1y). The manual annotation (Figure 6) was performed on seven species; , but for the training, only the three structural species in Zone 3 (A. transiens, D. cornigera and P. ventilabrum) were considered, resulting in 532 specimens, 705 colonies and 250 specimens of each species, respectively. From the high resolution images, a custom script generates the training and validation datasets $(80 \% / 20 \%)$ of 416x416px cropped images, adding the following data augmentation transformations: random shift, horizontal flip, vertical flip, resizing, brightness and color variations. Both the selection of annotated object and the amount of data augmentation is adjusted dynamically by the script to reduce the resulting class imbalance, which is a problem for this kind of datasets due to the huge difference in the number of specimens of the different species. The training procedure was performed with the default hyperparameters suggested by the yolov 4 author [57], although some of them were fine-tuned looking for the best performance. The final values of the most important ones are: Learning rate $=0.001$, Batch size $=16$, Subdivisions $=8$, native size $=416 \times 416 \mathrm{px}$.

The results of orthomosaic annotation processing obtained using this automatic process was validated against the manual annotation by an expert generated as input data for predictive habitat modeling. 


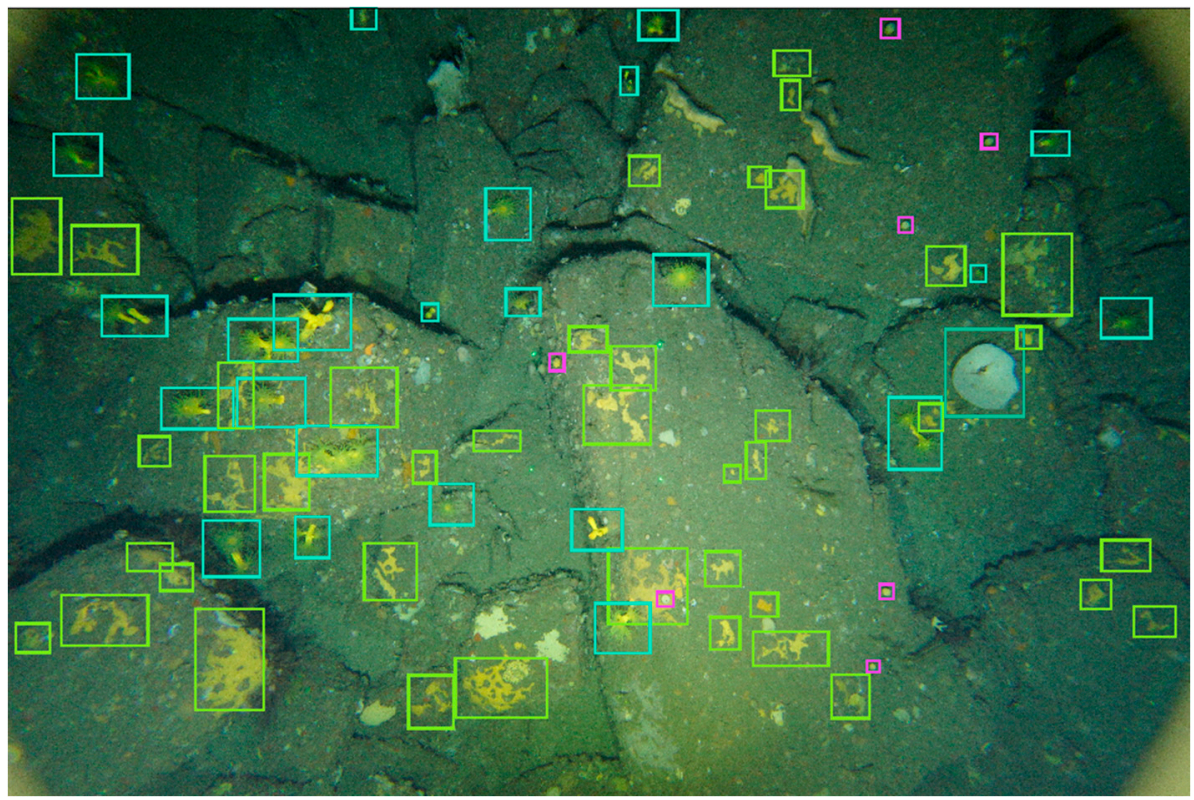

(a)

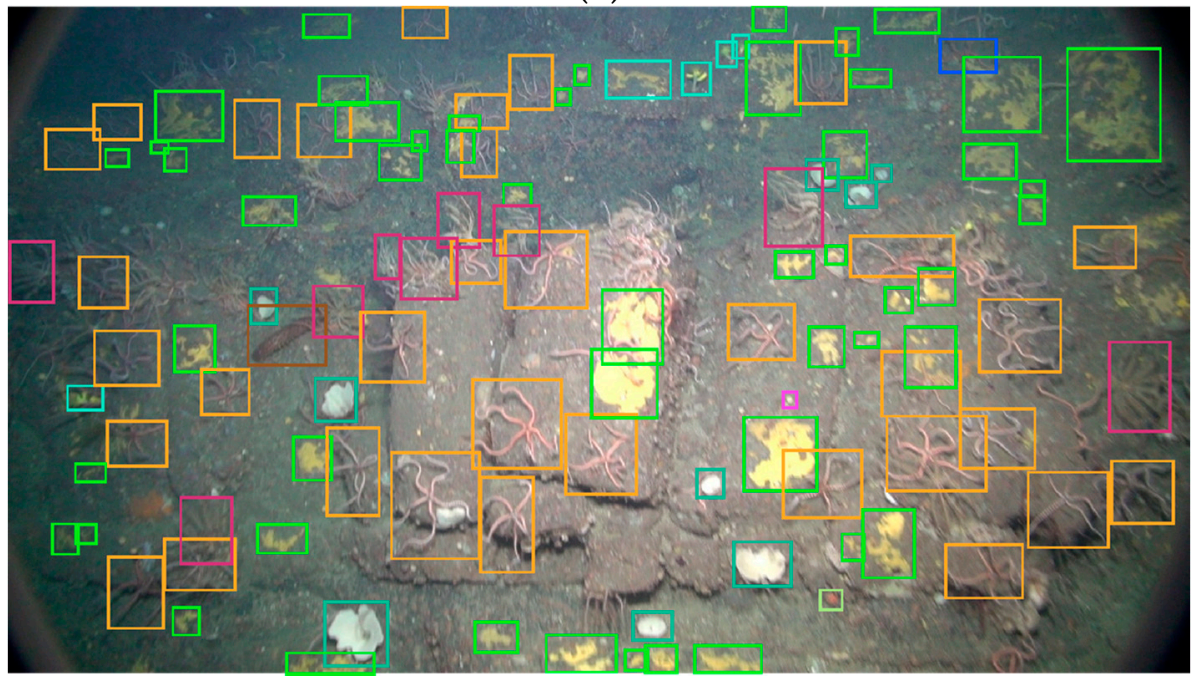

(b)

Figure 6. Examples of training dataset. Manually annotated images using Supervisely (a) example of annotation of one 24-Mpx photograph; (b) example of annotation of full HD video frame.

\section{Results}

\subsection{D Model, Digital Surface Model and Terrain Variables}

Individual 3D models were reconstructed for three study zones. Trajectory reconstruction and automatic tie point extractions were performed and a re-optimization of the model based on scales obtained from parallel laser beams was carried out. From these measurements, dense point clouds can be processed afterwards in high-density mode. A basic description of the characteristics of the 3D point clouds and orthomosaic processing performed is shown in Table 1. 
Table 1. Basic data regarding the image dataset and the 3D point cloud densification process.

\begin{tabular}{cccc}
\hline Summary & Zone 1 & Zone 2 & Zone 3 \\
\hline Longitude of video section $(\mathrm{m})$ & 91 & 48 & 25 \\
Area covered $\left(\mathrm{m}^{2}\right)$ & 421.5 & 93.3 & 60.1 \\
Average Ground Sampling Distance - GSD $(\mathrm{cm})$ & 0.23 & 0.14 & 0.05 \\
Number of calibrated images & 341 & 191 & 101 \\
Median of matches per calibrated image & 4268 & 4207 & 7290 \\
Number of 3D densified Points & 21833998 & 11590084 & 19864272 \\
Average density points $\left(\right.$ per $\left.\mathrm{m}^{3}\right)$ & 709,403 & $2.44 \times 10^{6}$ & $1.76 \times 10^{7}$ \\
\hline
\end{tabular}

Several scales were used for re-optimization of the geometric fitting of the models showing very low uncertainty (Table 2).

Table 2. Summary of scales of geometric uncertainty in 3D models.

\begin{tabular}{cccc}
\hline Summary & Zone 1 & Zone 2 & Zone 3 \\
\hline Mean reprojection error (pixels) & 0.209 & 0.202 & 0.196 \\
Number of scales & 9 & 2 & 3 \\
Initial length (m) & 0.200 & 0.200 & 0.250 \\
Mean computed length error (m) & 0.005 & 0.017 & 0.018 \\
X & & & \\
Y & 0.023 & 0.006 & 0.002 \\
Z & 0.034 & 0.008 & 0.004 \\
& 0.029 & 0.007 & 0.002 \\
\hline
\end{tabular}

According to Table 1, the average of GSDs in different zones is always below $0.5 \mathrm{~cm}$; so, although the presence of specimens is annotated in a maximum-resolution orthomosaic; in areas with faunal aggregations or specimens with considerable size, the extracted terrain descriptors are derived from the surface of these aggregations or these species. Based on the resolution of our model and the sizes of selected species specimens, all terrain descriptors were resampled to a pixel size of $5 \mathrm{~cm}$ to test for small-scale terrain morphometric characteristics. Therefore, from the digital surface model, slope, aspect (north and east), BPI, curvature and rugosity were obtained.

\subsection{Environmental Characteristics of Studied Sites and Faunal Presence}

The study areas are composed of a mainly rocky bottom, with some small sediment patches with very low slopes, which are always less than 3\%. In both Zone 1 and Zone 2, there are small steps of approximately $20 \mathrm{~cm}$, which are arranged in a transverse direction to the transect and are regularly spaced along the transect (Figure 7a,b). This seafloor morphology is common in this zone. In Zone 3 the bottom consists of adjacent rocky blocks of various sizes, between 10 and $20 \mathrm{~cm}$ in height (Figure 7c). Some small sedimentary-bottomed patches appear from time-to-time, without the presence of these blocks of rock that, given their sandy composition, do not present highlights or abrupt changes in elevation.

The target species in this study were annotated on portions of high-resolution orthomosaics in all study areas using QGis. In this way, a list of coordinates identifies the locations of presence/absence of specimens. An area of $20 \mathrm{~m}^{2}$ was selected in Zone 1; 341 specimens of the dominant species of brittle stars was annotated, obtaining a density of 17 specimens per $\mathrm{m}^{2}$. An area of $12 \mathrm{~m}^{2}$ was selected in Zone 2; 93 specimens of the L. celtica were annotated, obtaining a density of 7.75 specimens per $\mathrm{m}^{2}$. 


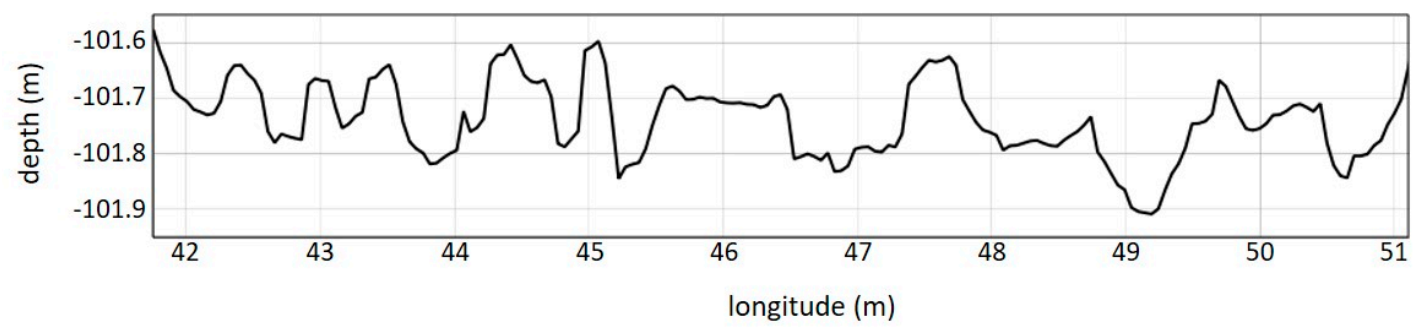

(a)

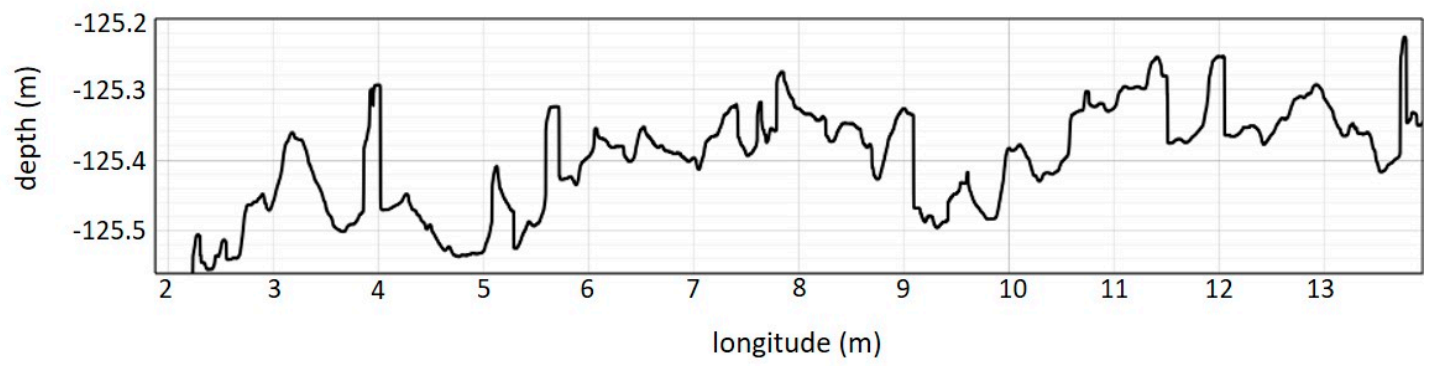

(b)

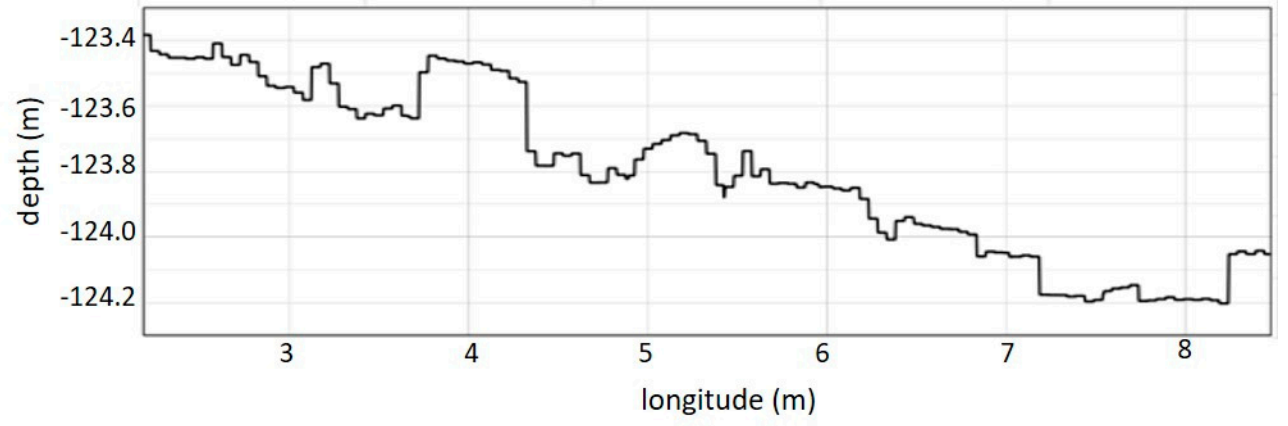

(c)

Figure 7. Details of longitudinal profiles from bathymetric layer at very fine-scale. (a) Zone 1; (b) Zone 2 and (c) Zone 3.

Finally, in Zone 3 there is no unique predominant species, but there is a concentration of different species, among which three (D. cornigera, P. ventilabrum and A. trasiens) were selected. In the high-resolution orthomosaic covering an area of $60 \mathrm{~m}^{2}$, the presence of all the specimens of these species was annotated: 206 colonies of $D$. cornigera $\left(3.43\right.$ colonies $\left./ \mathrm{m}^{2}\right), 56$ specimens of $P$. ventilabrum (0.93 specimens $/ \mathrm{m}^{2}$ ) and 120 specimens of $A$. transiens $\left(2\right.$ specimens $/ \mathrm{m}^{2}$ ). These coordinate lists of the instances was used as the input layer for the habitat suitability models.

Ripley's K indicated the distribution of ophiuroids is more clustered than a random distribution at distances greater than $0.13 \mathrm{~m}$ in Zone 1 (Figure 8), so the presence of ophiuroids displays distribution clustering points; while at smaller distances, the points were more dispersed than a random distribution. In Zone 2 the analysis of clustering of L. celtica positions shows a dispersed distribution over the sea floor at any distance from 0.05 to 1.5 metros (Figure 8b). In Zone 3 both the selected species, A. transiens and $D$. cornigera display a more clustered than random distribution at distances less than $1.3 \mathrm{~m}$ and P. ventilabrum shows this clustered distribution at distances from $0.2 \mathrm{~m}$ to $1.3 \mathrm{~m}$. 


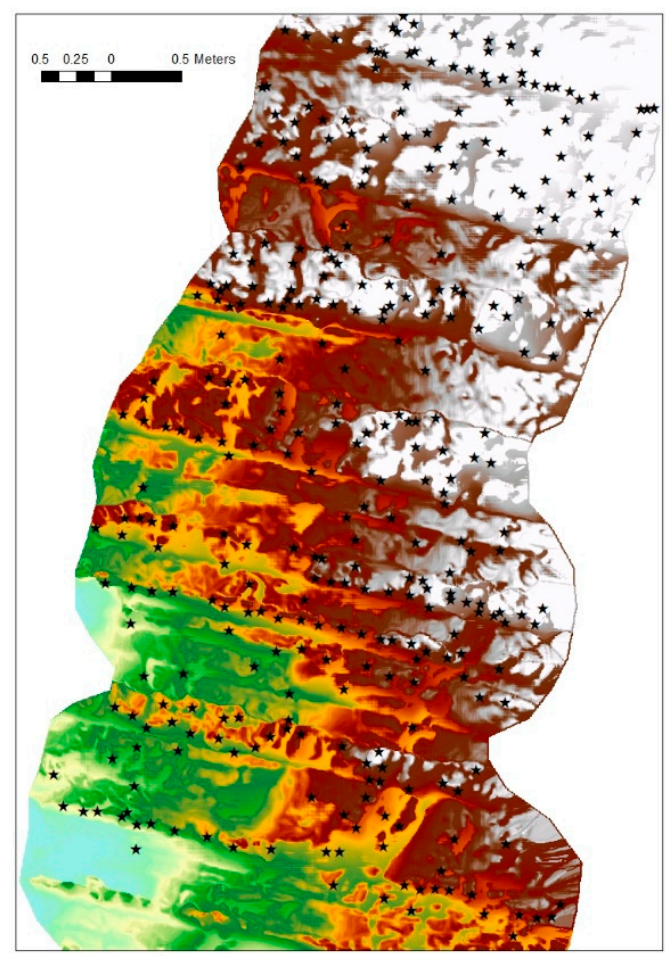

(a)

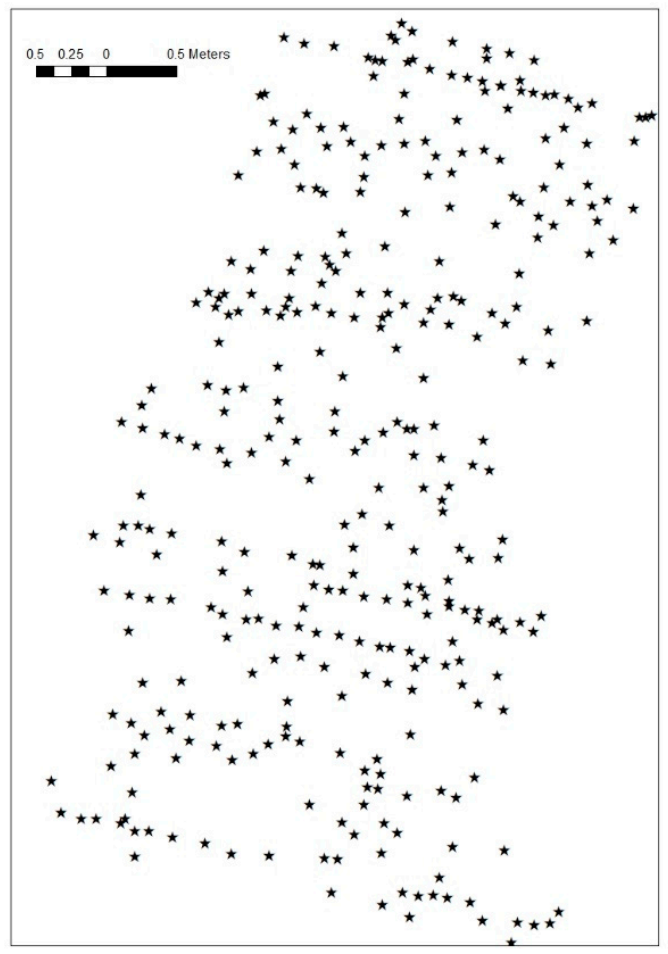

(b)

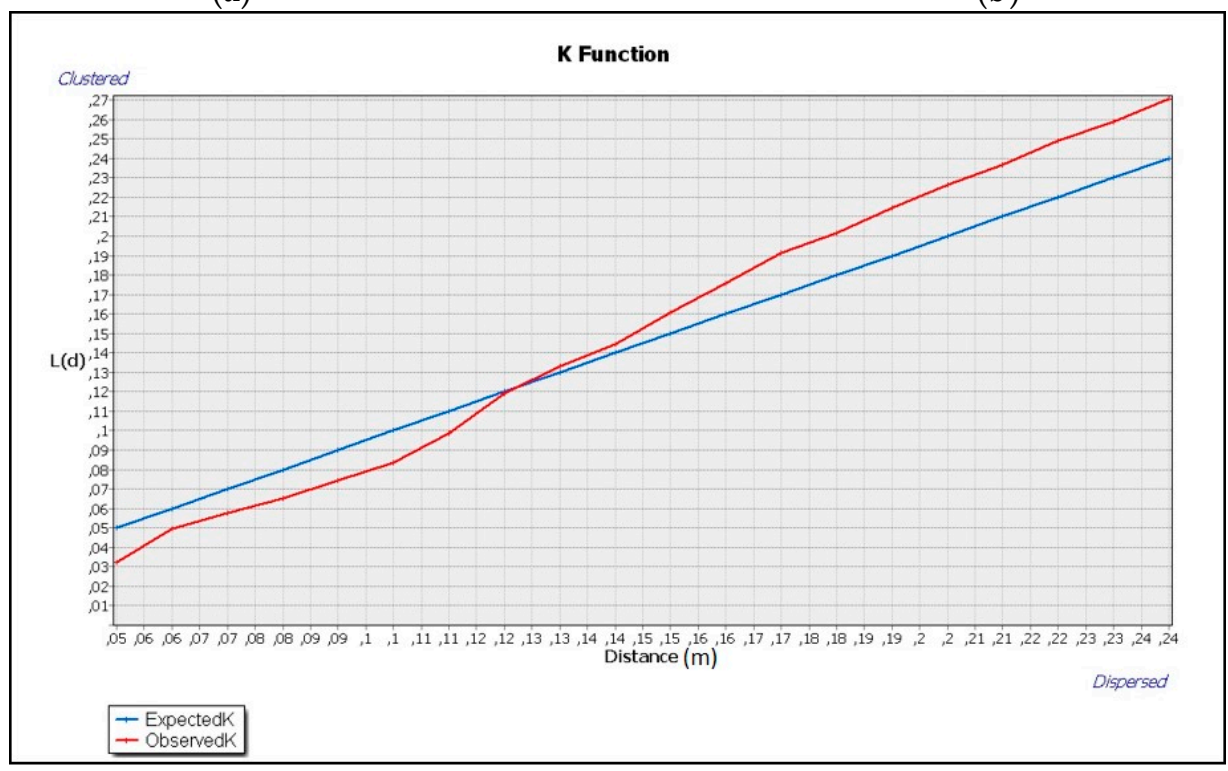

(c)

Figure 8. Unweighted $\mathrm{K}$ function results. When the observed $\mathrm{K}$ value is larger than the expected value, spatial clustering for that distance is statistically significant. When the observed $\mathrm{K}$ value is smaller than the expected value, spatial dispersion for that distance is statistically significant. (a) Zone 1, Ophiothrix fragilis, Ophiothrix sp. and Ophiura ophiura positions on high-resolution MDS; (b) Ophiuroidea geographic position layer (c) multi-distance spatial cluster results (Ripley's K function).

\subsection{Significant Terrain Variables and Habitat Suitability Model}

The depth variable was eliminated since at these fine scales the absolute altimetry differences within the same area are negligible as a condition that a species is present or not at a specific point. Therefore, the initial set of 6 environmental predictors: slope, aspect (north and east), BPI, rugosity 
and curvature were reduced to select the most explicative variables using a univariate approach. The variance inflation factors (VIF) showed collinearity between roughness and slope for Zones 1 and 2, so we avoided using slope as it had the highest VIF. Collinearity was not detected between terrain variables in Zone 3.

Deviance explained and adjusted R squared of univariate GAM models are shown on Table 3 for the most representative species of Zone 1 and Zone 2, with a unique selected species for each zone. The most important predictors for these areas are the bathymetric position index and the roughness. The first one explains about $40 \%$ of the variance of both zones. As for roughness, its contribution to the final model of Zone 2 is highly relevant, with more than $50 \%$ of the variance explained in the univariate GAM and it is also relevant for Zone 1, explaining 25\% of the variance.

Table 3. Results of univariable adjustment for terrain variables for Zone 1 and Zone 2. Shaded in gray, the predictors used for the final model of each species.

\begin{tabular}{ccc}
\hline \multicolumn{3}{c}{ R-sq.(adj)/Deviance Explained (\%) } \\
\hline Terrain Variables & Zone 1 & Zone 2 \\
\hline Aspect (North) & $0.014 / 2.54$ & $0.01 / 0.22$ \\
Aspect (East) & $0.015 / 2.8$ & $0.02 / 4.36$ \\
Bathymetric position index (BPI) & $0.320 / 38.7$ & $0.45 / 43.7$ \\
Curvature & $0.099 / 14.6$ & $0.33 / 31.5$ \\
Rugosity & $0.205 / 25.2$ & $0.57 / 50.2$ \\
\hline Final model & $0.515 / 55.2$ & $0.784 / 77.2$ \\
AUC & 0.951 & 0.986 \\
\hline
\end{tabular}

The univariate GAM results for Zone 3 are presented by target species in Table 4 . The most important predictor in this area for D. cornigera is the roughness, explaining about $30 \%$ of the variance, followed by the slope, which explains about $22 \%$. As for P. ventilabrum univariate models, roughness is the most important predictor with a value of $53.6 \%$ of the variance explained, followed by slope, which displays about $43 \%$. In the case of $A$. transiens, the univariate GAM shows $16 \%$ and $9 \%$ of explained variance for bathymetric position index and for roughness, respectively. Although these values are lower than the previous ones, they are the most important for this species.

Table 4. Results of univariate and final model general additive model (GAM) adjustment and deviance explained for terrain variables for Zone 3. Shaded in gray, the predictors used for the final model of each species.

\begin{tabular}{cccc}
\hline \multicolumn{4}{c}{ R-sq.(adj)/Deviance Explained (\%) } \\
\hline Terrain Variables & D. cornigera & A. transiens & P. ventilabrum \\
\hline Northness & Not significant & $0.03 / 3.51$ & $0.07 / 5.66$ \\
Eastness & $0.1 / 8.14$ & $0.03 / 2.6$ & $0.28 / 22.8$ \\
BPI & $0.11 / 11.1$ & $0.2 / 16.4$ & $0.26 / 22.6$ \\
Curvature & $0.08 / 8.77$ & $0.07 / 6.31$ & $0.29 / 25.9$ \\
Rugosity & $0.34 / 30.5$ & $0.1 / 9.21$ & $0.61 / 53.6$ \\
Slope & $0.22 / 22.5$ & $0.04 / 4.25$ & $0.49 / 43.7$ \\
\hline Final model & $0.56 / 53.5$ & $0.45 / 40.9$ & $0.66 / 62.4$ \\
AUC & 0.941 & 0.894 & 0.959 \\
\hline
\end{tabular}

As for the final models of the three zones (Figure 9), three predictors explain $55.2 \%$ of the variance in Zone 1, roughness, BPI and curvature. The same variables explain $77.2 \%$ of the variance in Zone 2 and finally, in the case of Zone 3,53.3\% of the variance is explained by roughness, BPI, Eastness and slope. AUC values (Tables 3 and 4 ) very close to 0.9 in all cases show very high reliability of predictions. 
Zone 1

$$
\begin{gathered}
\text { Pres/abs } \sim \mathrm{s}(\mathrm{bpi})+\mathrm{s}(\mathrm{rou})+ \\
\mathrm{s}(\mathrm{curv}) \\
\text { R-sq. }(\text { adj })=0.515
\end{gathered}
$$

Deviance explained $=55.2 \%$
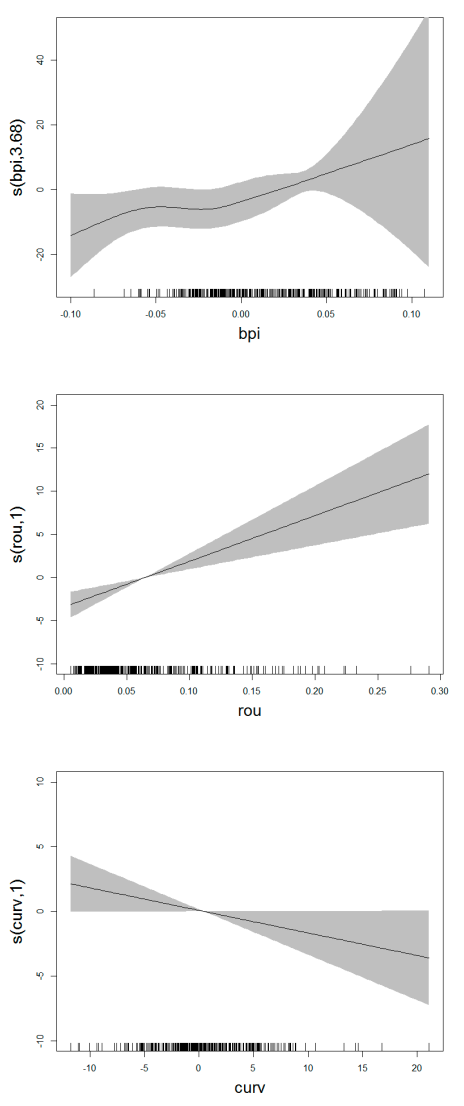

Zone 2

$$
\text { Pres/abs } \sim \text { s(bpi) }+\mathrm{s}(\text { rou })+
$$$$
\mathrm{s}(\text { curv, } \mathrm{k}=2)
$$

R-sq.(adj) $=0.784$ Deviance explained $=77.2 \%$
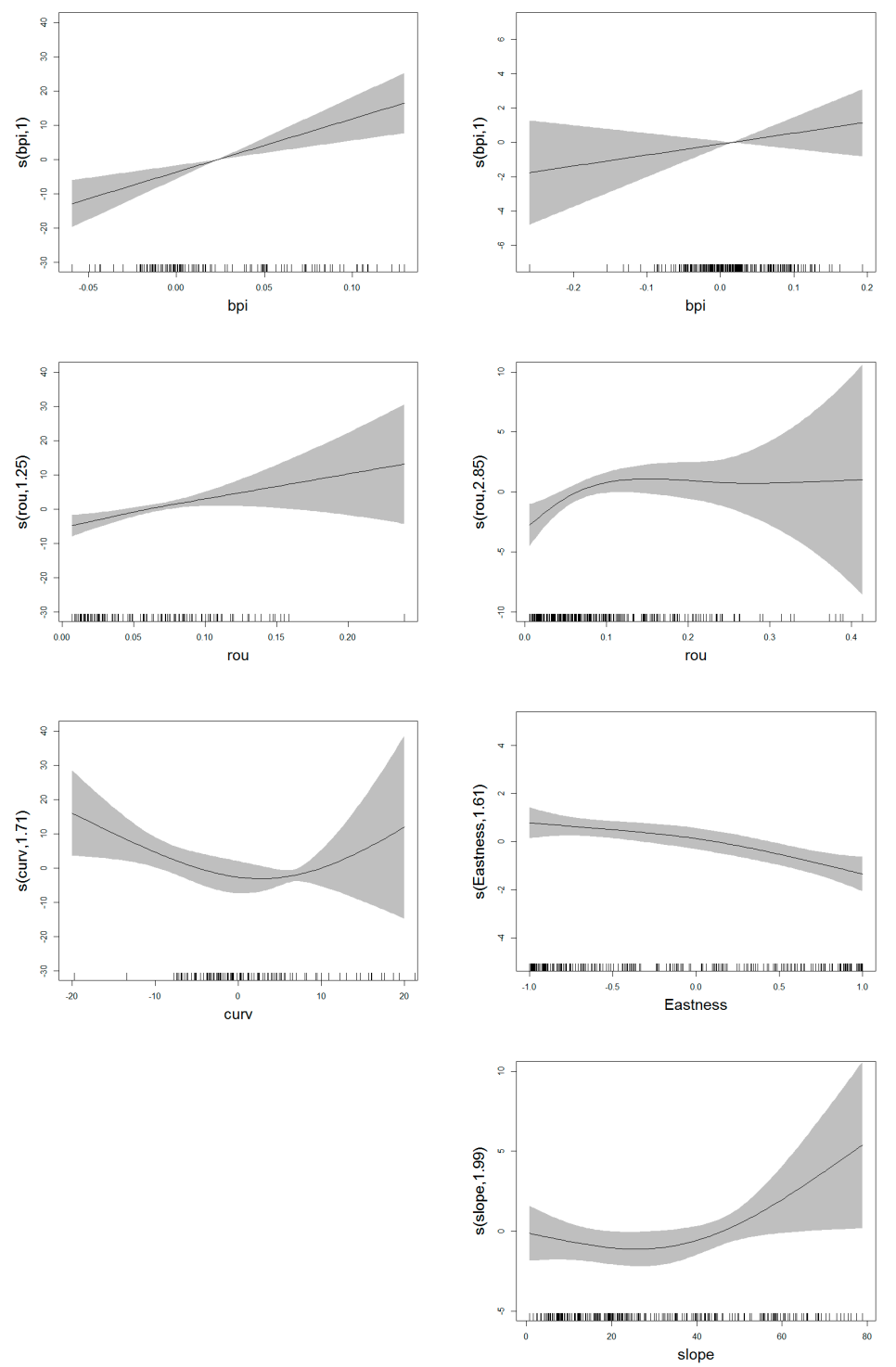

Figure 9. Final predictive models and curves for each of the zones. Zone 1 corresponding to the O. fragilis, Zone 2 to L. celtica and Zone 3 to D. cornigera.

The probability of occurrence of the species studied in all the areas increases directly as the BPI and roughness become higher. However, to a certain extent, when presence decreases, confidence bands become wider. Thus, the presence of the brittle stars is not relevant above a BPI value of 0.05 in Zone 1, 0.1 in Zones 2 and 3 or above a roughness value of 0.1 . On the other hand, the curvature has a negative relationship with occurrence in Zones 1 and 2; and Eastness and slope and the rest of the significant predictors of Zone 3, do not display a clear tendency. 
The models designed enabled the generation of detailed maps with the spatial distributions expressed as probability values (Figures 10-14), identifying the environmental characteristics required for each of the selected species. These models were run with data based on the presence and absence of the selected species annotated in very high spatial resolution orthomosaic and with representative values of abundance in the area.

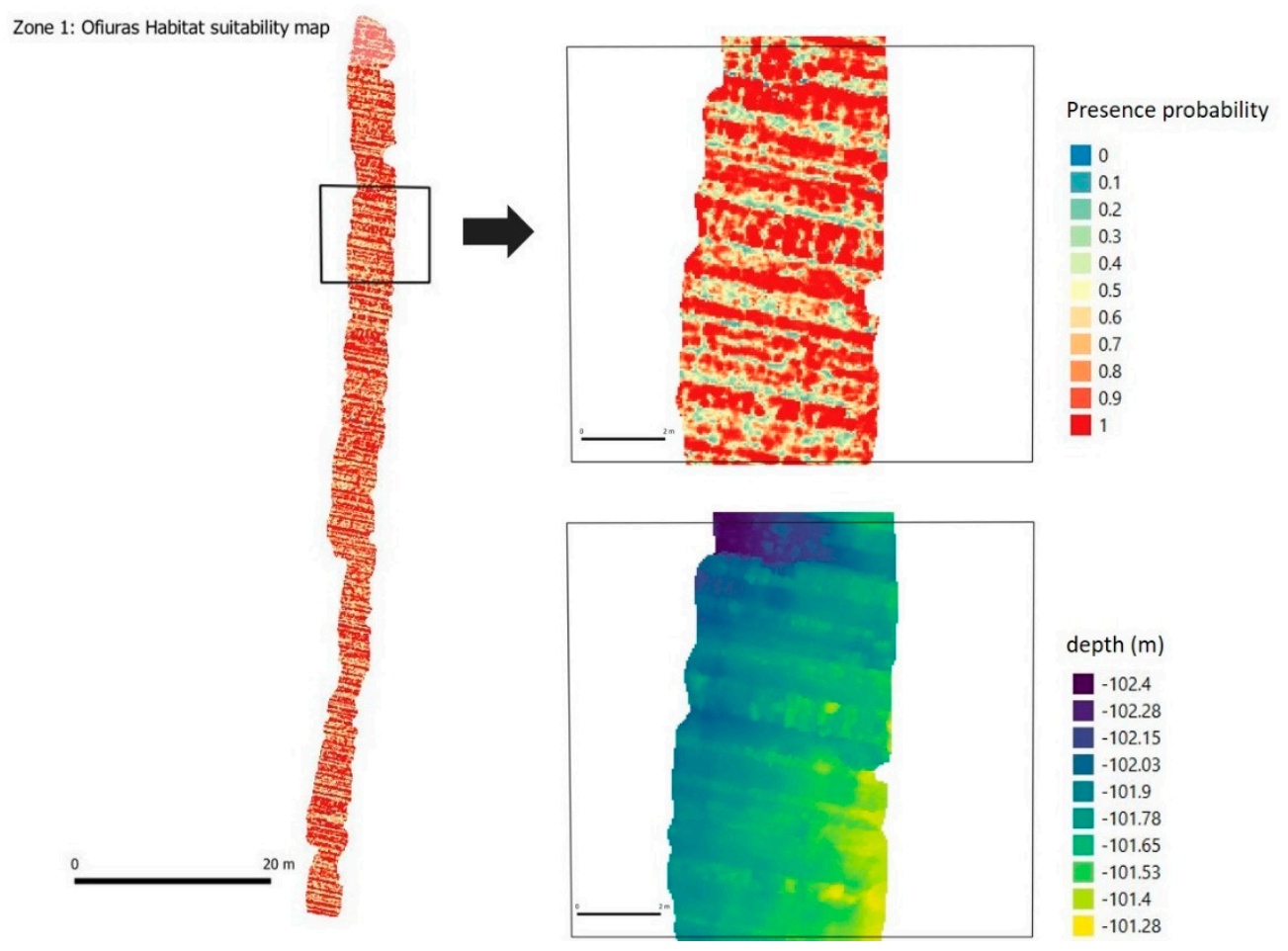

Figure 10. Habitat-suitability maps from 0 (no suitability) to 1 (full suitability) created using final predictive models over test Zone 1 (Class Ophiuroidea).

Zone 2. Leptometras Habitat Suitability Map

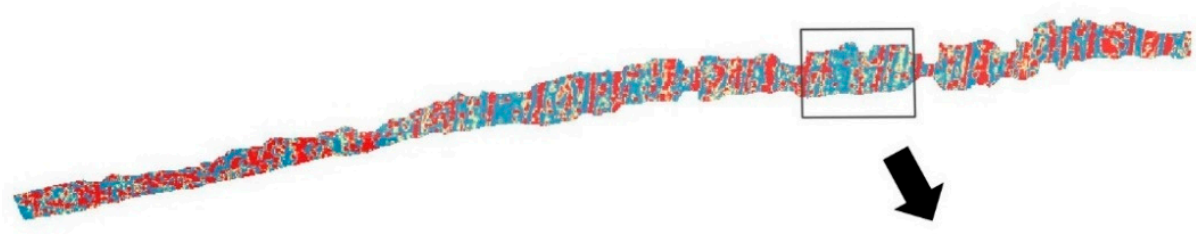

$10 \mathrm{~m}$
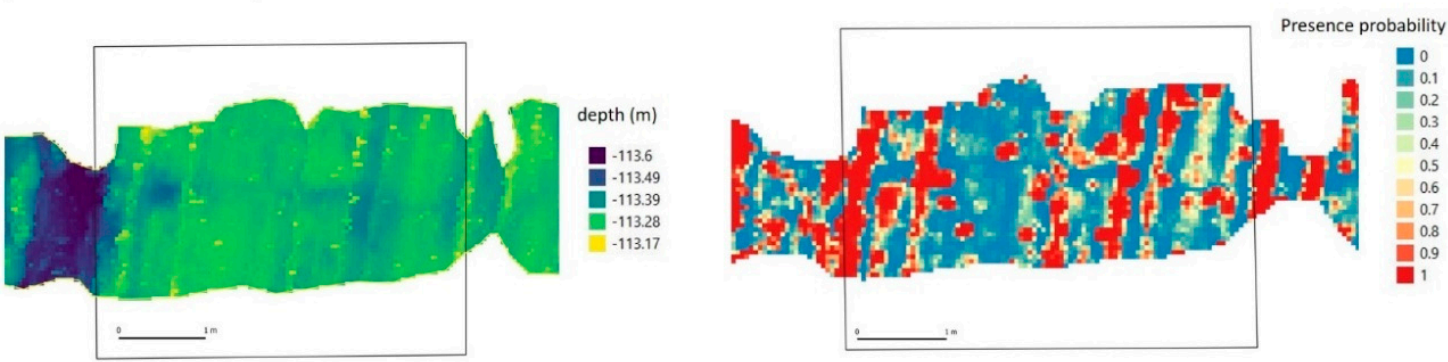

Figure 11. Habitat-suitability maps from 0 (no suitability) to 1 (full suitability) created using final predictive models over test Zone 2 (L. celtica). 
Zone 3. Artemisina Habitat Suitability Map

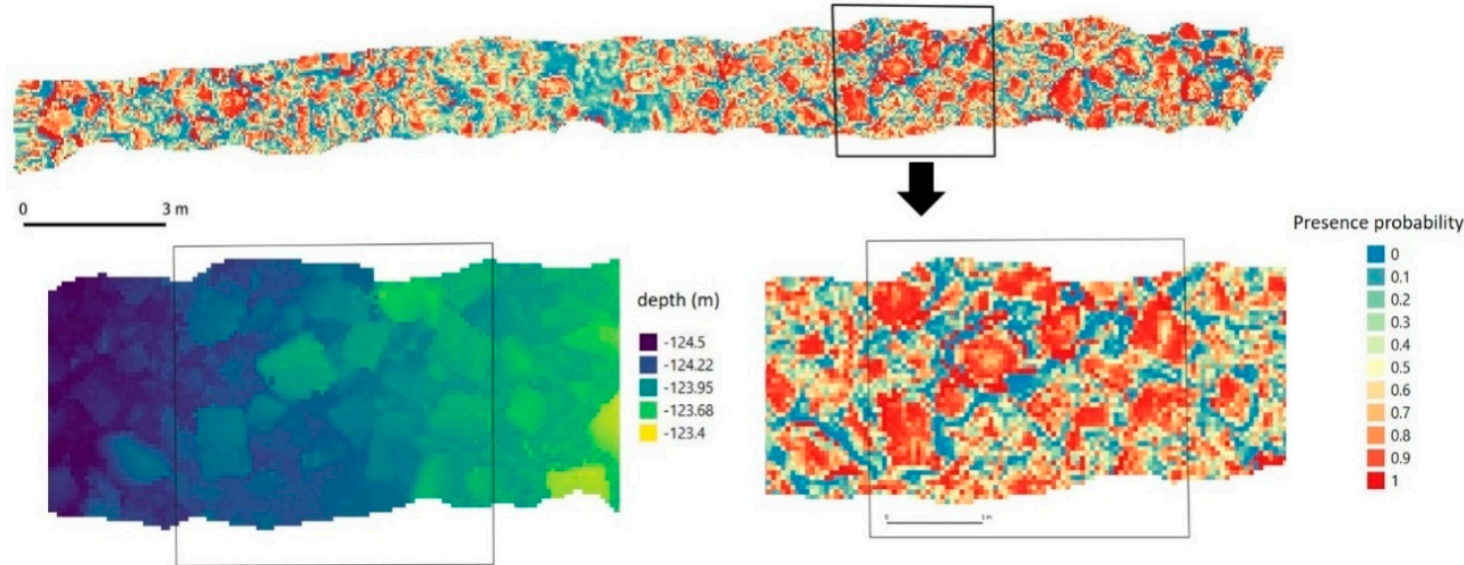

Figure 12. Habitat-suitability maps from 0 (no suitability) to 1 (full suitability) created using final predictive models over test Zone 3 (A. transiens).

Zone 3. Dendrophillia Habitat Suitability Map
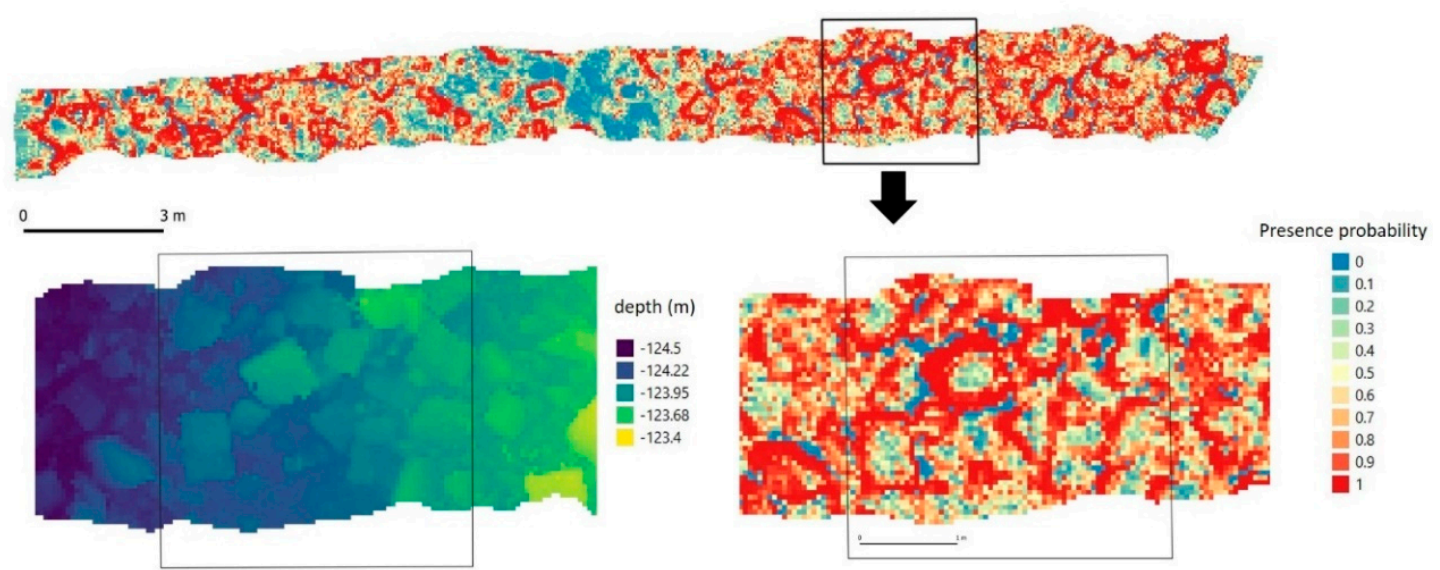

Figure 13. Habitat-suitability maps from 0 (no suitability) to 1 (full suitability) created using final predictive models over test Zone 3 (D. cornigera).
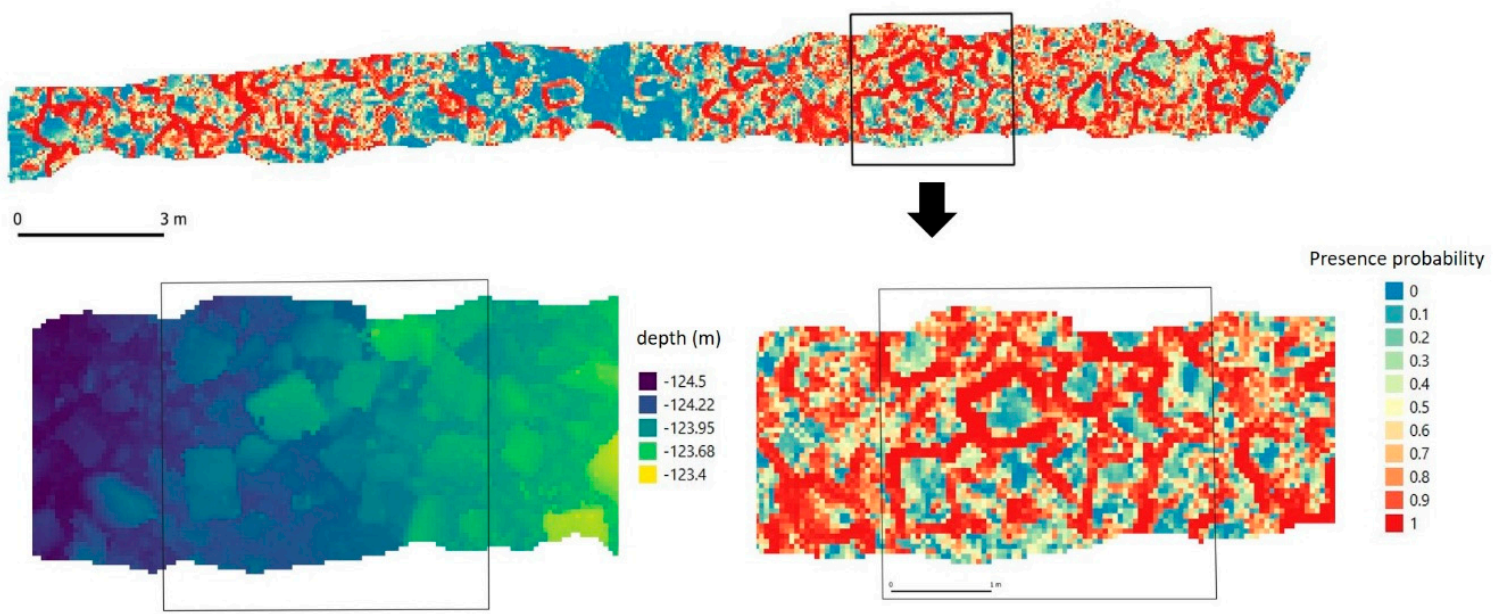

Figure 14. Habitat-suitability maps from 0 (no suitability) to 1 (full suitability) created using final predictive models over test Zone 3 (P. ventilabrum). 
In general terms we can summarize by indicating that all the target species studied have environmental preferences for abrupt rocky facies (high rugosity and extreme values of BPIs) with low or null sedimentary coverage. The Ophiuroidea species prefer to be emplaced on the depressions located between the ridges of these rocky bottoms (Figure 10). The crinoid L. celtica have environmental preferences for the small ridge borders (Figure 11). The sponge Artemisina shows clear preference for the upper flat areas of boulders (or rocky blocks) characterized by positive BPIs (Figure 12). On this ground type with boulders, the yellow coral (D. cornigera) has a preference for the edges of blocks (high values of slope and rugosity), with what appears to be spatial segregation with respect to the previous sponges, which settle on central areas of boulders (Figure 13). Finally, the cup sponge (P. ventilabrum) shows similar environmental preferences to the yellow coral, but even more restrictive than this (Figure 14).

\subsection{Automatic Presence Record Annotation}

The performance of the trained network was tested using the orthomosaic of Zone 3. It is a very high-resolution image $(0.05 \mathrm{~cm} /$ pixel $)$ with 132 specimens $A$. transiens, 213 colonies $D$. cornigera and 62 specimens $P$. ventilabrum, not included in the training or validation dataset. The large image was cropped in $416 \times 416$ px images with $30 \%$ overlap among them and processed by the trained network. The coordinates of the detected individuals in each cropped image are then traced back to the original orthomosaic. As the overlap results in some individuals being detected multiple times, a non-max suppression algorithm was applied to overlapped bounding boxes. Figure 15 shows some examples of the automatically detected and identified specimens.
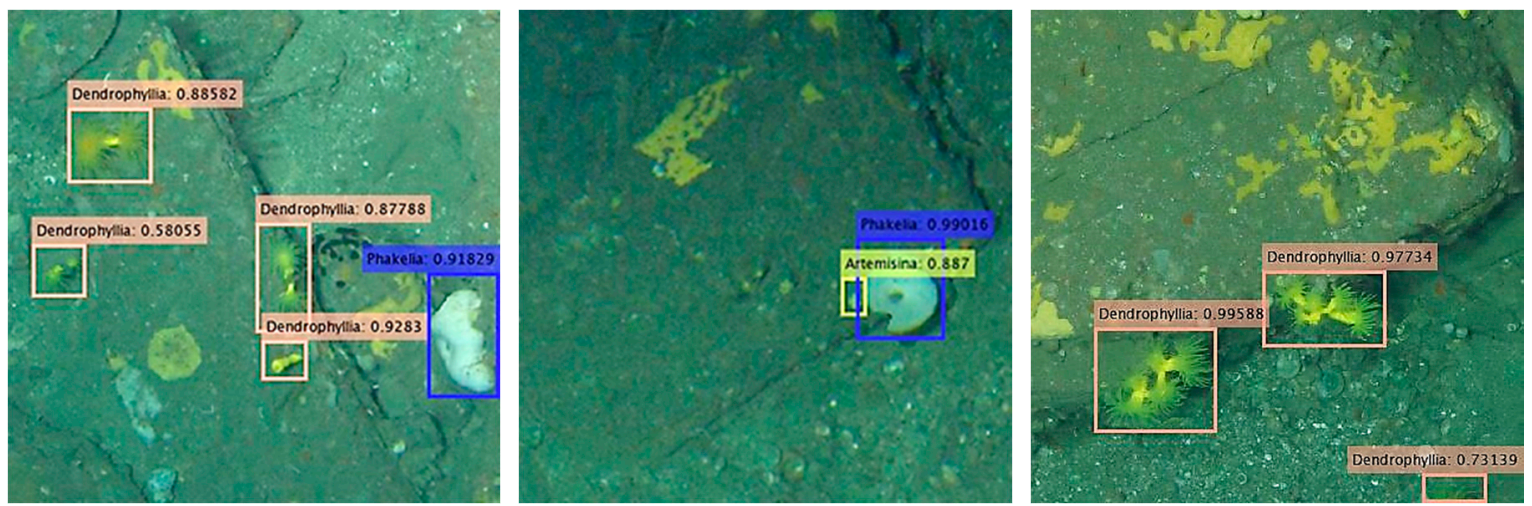

Figure 15. Some examples of the automatically detected and identified specimens in cropped images. In this figure, it can be seen that the network is able to identify even cropped individuals or colonies, in the case of $D$. cornigera and to correctly locate and bound each one. The numbers indicate the probability assigned by the inference process.

An objective indication of the network performance can be extracted from the confusion matrix derived from the processing of the orthomosaic of Zone 3 (Table 5).

In the overall performance (Table 6), it can be seen that the mean average precision is very high (i.e., species are correctly identified), but there is also a high number of false positives, that is, areas of sea floor and encrusting yellow species incorrectly identified as one of the three structuring species. Performance is poorer for the species $A$. transiens, due to the high number of false negatives (individuals not detected). 
Table 5. Confusion matrix for the test of the trained yolov4 network against the orthomosaic of Zone 3. The class "background" for the ground truth refers to the image areas not annotated (sea floor and other species) that were incorrectly identified as one of the three species (false positives); for the predicted specimens, "background" refers to individuals not detected (false negatives).

\begin{tabular}{ccccccc}
\hline & \multicolumn{5}{c}{ Predicted } \\
\cline { 3 - 7 } & & P. ventilabrum & D. cornigera & A. transiens & Background & Total \\
\hline \multirow{4}{*}{ Truth } & P. ventilabrum & 54 & 0 & 0 & 8 & 62 \\
& D. cornigera & 0 & 145 & 0 & 68 & 213 \\
& A. transiens & 0 & 0 & 87 & 45 & 132 \\
& Background & 38 & 66 & 71 & - & 130 \\
& Total & 92 & 211 & 158 & 121 & - \\
\hline
\end{tabular}

Table 6. Performance metrics for the test of the trained You Only Look Once, version 4 (YOLO v4) network against the orthomosaic of Zone 3.

\begin{tabular}{cccc}
\hline & P. ventilabrum & D. cornigera & A. transiens \\
\hline True positives & 54 & 145 & 87 \\
False positives & 38 & 66 & 71 \\
False negatives & 8 & 68 & 45 \\
Precision & 0.59 & 0.69 & 0.55 \\
Recall & 0.87 & 0.68 & 0.66 \\
f1-score & 0.70 & 0.68 & 0.60 \\
Mean average precision & & 0.61 & \\
Mean recall & & 0.74 & \\
Mean f1-score & & 0.66 & \\
\hline
\end{tabular}

\section{Discussion}

This study combined 3D photogrammetry, predictive suitability models and deep-learning techniques to improve our knowledge about benthic microhabitat in the Bay of Biscay circalittoral zone. All data sources are obtained and used at very fine-scale $(\sim \mathrm{cm})$. We present the resulting habitat mapping of three zones of the circalittoral zone dominated by different predominant species in each one. Bathymetric characteristics were obtained from 3D models constructed from very high-resolution optic images. Additionally, a new deep-learning approach was validated to use it in records of presence of species. Although previous manual training is required, the automatic performance of the network presented here represents a breakthrough in the field of underwater image annotation.

The results show the utility of this methodology for circalittoral auto-ecology, species behavior and food habits. It can also be useful to improve data for monitoring and management measures in the spatial planning context (i.e., Marine Spatial Planning, Nature Network 2000 or Marine Strategy). In the following sections we discuss the main aspects analyzed in this study, the advantages and limitations.

\subsection{D Photogrammetry to Improve Habitat Suitability Models}

Nowadays, the presence of species in benthic habitats is usually obtained from annotated photographs or video transects. The recent improvements in underwater optic sensors (e.g., geo-referenced underwater high-resolution photos, full HD and $4 \mathrm{k}$ video) result in an availability of information about species location with a very high spatial scale. Therefore, there is an inconsistency between the magnitude used for terrain descriptors extracted from acoustic technology and the scale used for determining the presence/absence and density of species of interest. Habitat modeling is limited to the scale at which seafloor characteristics can be resolved, based on the maximum resolution of the data. A similar problem is described in [13] with a disparity in the scale of features that can be resolved between high-resolution acoustic data sets and the broader oceanographic data sets (i.e., temperature, salinity, etc.). What happens when combining data obtained from different sources (underwater images, acoustic systems, oceanographic and biologic data) in producing habitat maps? The coarse scale at 
which one type of data can be accessible determines the working scale of study that can be carried out on the area and the results obtained. The global approach can produce sufficiently optimistic models in cases like coral occurrence. The frequency of coral occurrence observed in analyses of survey photographic data were much lower than expected and patterns of observed versus predicted coral distribution were not highly correlated [58].

Structure-from-motion techniques can achieve spatial resolution that can be orders of magnitude greater than are achieved by other methods such as large-scale lidar and sonar mapping of coral reef ecosystems [59]. Thus, 3D photogrammetry is a powerful resource for characterizing benthic habitat complexity based on terrain details at very fine scale. Contributions from these approaches combined with habitat/species distribution models are substantially advancing the knowledge about the relation of environmental data and habitat/species at very high geographic scales. The use of the 3D photogrammetry approach using underwater images enables the generation of three-dimensional maps at sub-centimetric scale. structure-from-motion (SfM), allows the simultaneous mapping of organisms and bathymetric variables at fine scale, avoiding the problem of the different resolutions of data. It should not be forgotten, however, that this approach sacrifices the size of seafloor area covered in the studies. These 3D cartographic products are very useful for understanding of fine-scale ecological processes, such as the structural complexity of benthic habitats. Three-dimensional structure of habitats plays a fundamental role in the localization of species. 3D maps are increasingly accessible to researchers and allow them to establish different studies for spatial ecology understanding [60].

Incorporating microhabitat distribution could significantly enhance the evaluation of efficiency of reserves and benthic habitat modeling. One of the most emblematic habitats that has been the subject of many studies in the marine environment are coral reefs. Coral reef habitat structural complexity influences key ecological processes, ecosystem biodiversity and resilience. In this environment, the efficiency of marine reserves may be influenced by the availability of suitable decimetric scale habitats ("microhabitats") for species of low mobility or sessile macroinvertebrates [61]. Structure-from-motion photogrammetry has proven to be a useful tool for understanding the structural complexity of the coral reefs studied. The efficiency of this technique has been demonstrated in quantifying multiscale habitat structural complexity comparing it with dive measurements [32] or with laser reference models [62]. Using this approach, $[63,64]$ show that coral assemblage structure acts as a significant driver of 3D structural complexity of coral reef habitats.

Beyond evaluating the complexity of the habitat, these fine-scale bathymetric variables can be used to study the location in $3 \mathrm{D}$ space of small organisms. This enables the verification of the influence of the terrain's morphometric characteristics on different species behavior. It is rare to find works that address habitat modeling at centimeter scales in marine environment. However, this type of methodology enables the study of ecological characteristics and environmental preferences in small species; the study in detail of areas with high habitat fragmentation and improvement in knowledge of the relationships between specimens of the same species or between species with similar environmental niches (association and competitiveness). There are areas where the morphometric complexity of the terrain conditions the formation of a specific type of habitat. In addition, these terrain characteristics complicate access to study zones. In [35], high-resolution mapping of vertical marine features were presented, based on SfM and spatial patterns in ecological characteristics were explained. A very similar methodological approach is used in [36]. In this case, it is also a morphometrically peculiar area since 3D modeling and predictive habitat suitability models are used to discriminate the environmental preferences of hydrothermal vent faunal assemblages. Besides morphometric terrain variables, the distance to diffuse and black fluid is used too, demonstrating the potential of knowing very precise specimen positions on the sea floor. Unfortunately, no similar studies have been conducted in circalittoral zones.

The prediction models presented here show AUC values very close to 1, associated with very high degrees of accuracy. AUC scores with the maximum achievable value of one imply perfect discrimination of validation data [58]. This represents the ability of the models presented here to 
predict presence at very fine spatial resolution scales. This high prediction capacity is based exclusively on the microbathymetric characteristics of the terrain. Therefore, this methodology can be used for modeling microhabitats in areas of high complexity due to their fractionation or ecological patching.

\subsection{Spatial Distribution and Behavior of Species}

The habitat suitability models can be used to improve our knowledge about environmental preferences in location of different species, conditioning the behavior of the specimens.

An example explained above is found in the results obtained in the analysis of significant environmental terrain variables in Zone 1 and 2 (localizations of ophiuroids and L. celtica, respectively). These species live in places with strong currents and in large aggregations. This behavior of living in dense patches maximizes their efficiency in the access to food as suspension feeders [65]. The results show that the positions chosen by the specimens of these species depend on the same environmental derivatives of the terrain (bpi, curvature and roughness), seeking maximum turbulence in the microscale range. This indicates that if two population groups of these species coincide in space, they will compete for the same locations since they have the same environmental preferences. This issue can be verified with images taken precisely in an area close to the study areas (between Zone 1 and Zone 2), where numerous specimens of these species can be found. Figure 16 shows the specimens of Ophiuroidea and L. celtica located on the same ground positions even when there are free parts of the sea floor.
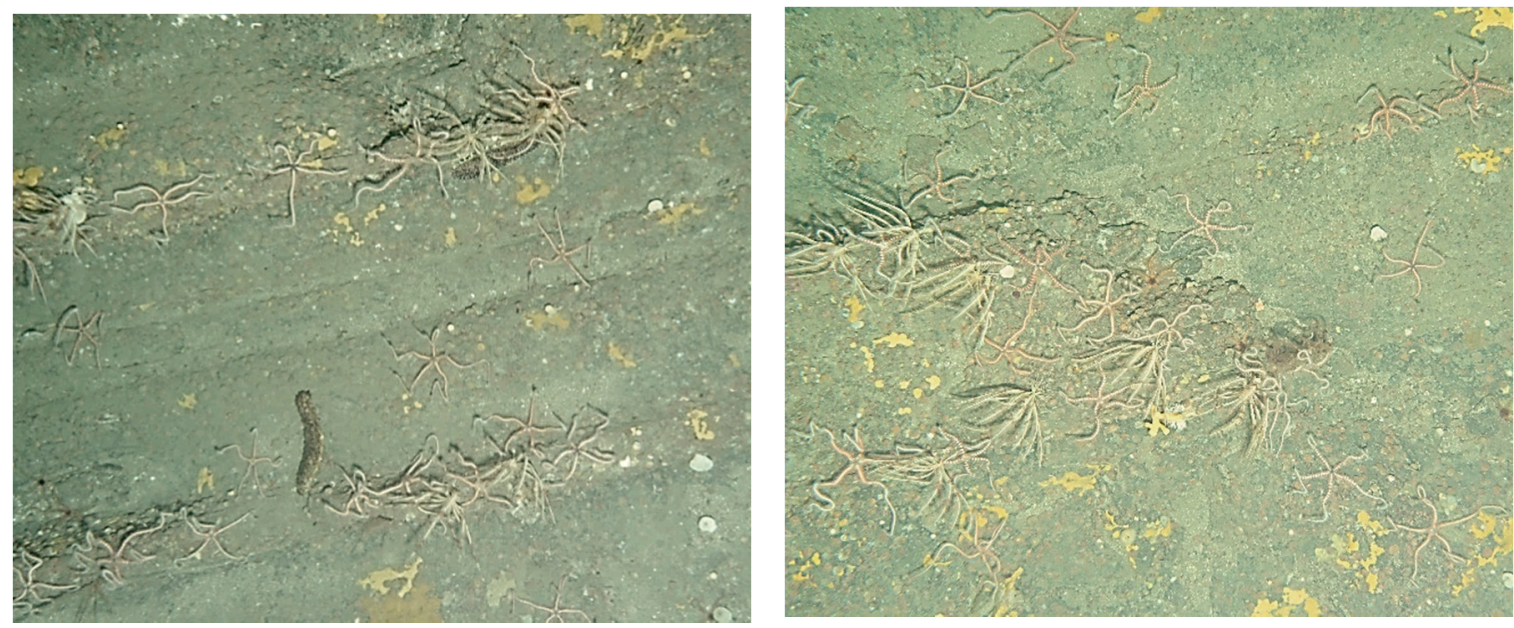

Figure 16. Two details of images where the positions selected on the seafloor by Ophiuroidea and L. celtica specimens can be observed.

The dispersion of the specimens in Zones 1 and 2, through the Ripley's K of these species, however, shows dissimilar results. The Ophiuroidea tend to form clusters of specimens when they are at distances greater than $13 \mathrm{~cm}$ (Figure 7a); roughly corresponding to the size of the specimens recorded in this study. However, the Crinoidea show a scattered distribution in the terrain in the range of scales studied (Figure $7 \mathrm{~b}$ ). This could be interpreted in L. celtica as behavior that minimizes competition between individuals related to food availability, since they are filter feeders. However, the spatial distribution of the Ophiuroidea, even when specimens of different species coexist, does not show any problem in sharing the same space. This behavior may be influenced by the lesser dependence of ophiuroids on water currents that carry organic matter, since a large proportion of their food is deposited or fixed in the ground

A. transiens was found forming dense aggregations always on rocky beds, in the Bay of Biscay and Northwest of Iberian Peninsula [3]. In the visual analysis of photographs, we can see that these small sponges are fixed to the flat faces of the stone blocks, seeking clear areas, but without large slopes or sudden changes (Figure 17). This coincides with the predictive analysis (Figure 12) in which the 
highest probability of occurrence was precisely in these places. Data on spatial distribution patterns in this case may be associated with the range of larvae with survival success and the distances to which they are fixed. According to the results of the Ripley's K analysis, this maximum dispersion distance could be set at $1.5 \mathrm{~m}$ approx. Below this distance the specimens of this species show a distribution of groups.

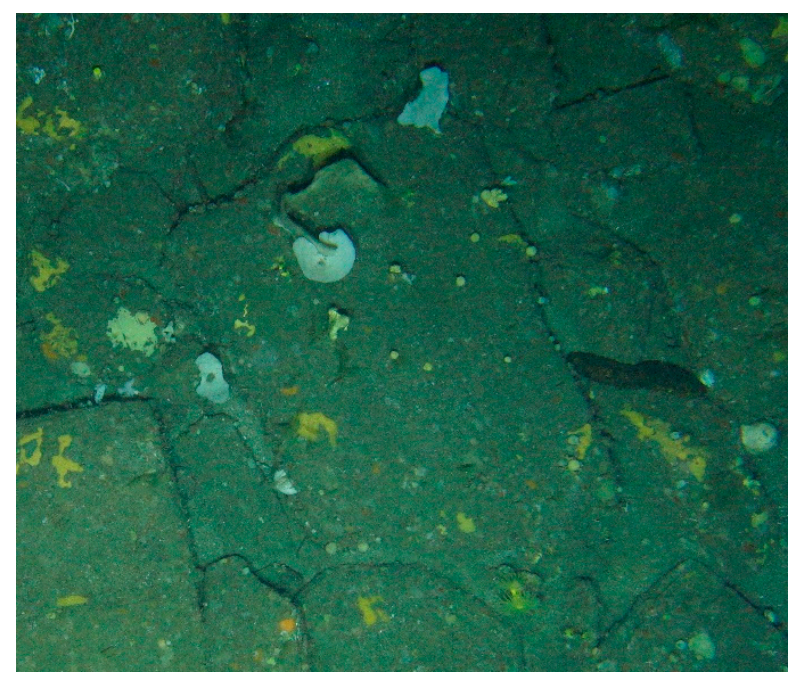

Figure 17. Detail of image where an aggregation of $A$. trasiens located on a flat face of a rock can be observed.

D. cornigera, usually forming low patches with a mean size of about $30 \mathrm{~cm}$. This species is colonial, forming three-dimensional structures growing by extra-tentacular budding on hard bottoms. Typically, it has a small and bushy colony with sparse irregular branching [66]. Among the environmental preferences that influence its location, the roughness of the terrain stands out. This can be mainly attributed to their diet, based on the capture of zooplankton present in the water, therefore choosing areas of greater turbulence and resuspension of food. Visually, the images show how the colonies are usually arranged on the edges of the stone blocks, fixing their base on them and extending the polyps towards the clearest areas (Figure 15). This same behavior in location preferences is reflected in the habitat suitability map (Figure 13).

In the Bay of Biscay, P. ventilabrum was found forming small cups or funnels with thin walls and a short peduncle on rock ridges and outcrops. At the microscale range, the environmental preferences of this species focus mainly on roughness and both in the images and in the habitat suitability model (Figure 14), a distribution very similar to D. cornigera can be seen, although unlike the latter, BPI is not among its restrictions and it can be found both on edges with a clear horizon and on sunken rock edges.

\subsection{Implementation of Deep-Learning Techniques to Annotate Benthic Species in Images}

In all habitat predictive models, it is necessary to incorporate biologic information in order to create a benthic habitat map. Habitat predictive models require a representative number of geographic locations of specimens of the different species [39]. The automation of the image annotation process is, in fact, one of the clearest requirements of researchers and one of the issues that will enable underwater investigation of the benthos to take a further step forward.

From the above-described automatic detection algorithm using the trained network, it is possible to get the location of every individual over the orthomosaic, even with geographic coordinates. This information could then directly feed the microhabitat predictive models. Moreover, this approach can contribute to automate generation of density maps of selected species.

Although the performance of the YOLO v4 deep learning network after training with our custom dataset is similar to other object detection networks reported in the literature, there is room for 
improvement of the merit figures. In future works, we plan to improve our dataset with more annotated images and use different detection threshold for each specie, which we hope will improve the detection of small species such as A. transiens. The careful choosing of the overlap threshold of the non max suppression algorithm should also help with the correct identification of specimens in D. cornigera colonies. Additionally, we plan to train the network with all the species found in Zones 1 , 2 and 3 , so the algorithm could be used in more diverse areas.

\section{Conclusions}

We provided evidence that using a SfM approach and terrain-derived variables at centimetric scales, predictive microhabitat models can be designed with very high confidence levels. A 3D reconstruction model of a circalittoral rock area of a portion of the Bay of Biscay continental shelf enabled the characterization of some habitats in circalittoral rocky zones, extracting terrain variables from 3D model to find the principal factors that explain species location. These models enable the advance in knowledge about the factors that affect the space distribution among specimens of different or the same species at very fine scales.

The accurate classification of benthic habitats in circalittoral ecosystems is essential for developing realistic management strategies. However, automatic or semiautomatic approaches for deriving species identification, localization and quantification from underwater images are still scarce. The deep-learning-based approach presented here for the automatic annotation of images is very promising.

Author Contributions: All authors conceived and designed the study. Analyzed the data: E.P., A.R.-B. and A.C. Identified fauna: A.R.-B. and P.R. Photogrammetry and Structure from motion techniques: E.P. Predictive Habitat Modeling, A.R.-B. Deep-learning techniques: A.C. Led the ship surveys: F.S. Processed the video/image material: E.P., A.R.-B., A.C. and P.R. Taxonomy information: P.R. Acquired funding: F.S., E.P. and A.C. All authors prepared figures and tables. All authors reviewed drafts of the study. All authors helped to write the manuscript. All authors have read and agreed to the published version of the manuscript.

Funding: This research was partially funded in the scope of the European Commission LIFE+ "Nature and Biodiversity" call and included in the LIFE IP INTEMARES project (LIFE15 IPE/ES/000,012). Moreover, it was partially funded by the Spanish Science and Technology Ministry and included in the ECOMARG (Scientific and technical assistance for the declaration, management and protection of MPAs in Spain) Project (REN2002-00,916/MAR). Deep-learning advances presented here are part of Deep-RAMP (Deep learning to improve the management of marine protected area network in the North Atlantic region) project funded in the frame of the Pleamar Program of the Biodiversity Foundation of the Ministry for Ecological Transition and is co-financed by the European Maritime and Fisheries Fund (EMFF).

Acknowledgments: This study was made possible thanks to the invaluable work of all the participants in the two surveys involved and the crews of the R.Vs. Ángeles Alvariño (IEO) and Ramón Margalef (IEO). The authors also appreciate the helpful assistance of the technicians of the ROTV Politolana, for their skill in executing the dangerous visual transects very close to the rough bottoms of the study area. The authors would like to thank Pedro Anuarbe Cortes, Guillermo Díaz San Martín and Sergio Sierra Menéndez for their contribution to the development and testing of the deep-learning algorithms and dataset.

Conflicts of Interest: The authors declare no conflict of interest. The funders had no role in the design of the study; in the collection, analyses or interpretation of data; in the writing of the manuscript or in the decision to publish the results.

\section{References}

1. Council of Europe; Group of Experts on Protected Areas and Ecological Networks. Interpretation Manual of the Habitats Listed in Resolution No. 4 (1996). Listing Endangered Natural Habitats Requiring Specific Conservation Measures; Third Draft Version 2015; Council of Europe: Strasbourg, Franch, 31 August 2015; T-PVS/PA (2015) 9.

2. Sánchez, F.; Rodríguez-Basalo, A.; Gómez-Ballesteros, M.; Prado, E.; Patrocinio, T.; Ríos, P.; Punzon, A.; Rueda, J.; Cristobo, J. Habitats characterization of circalittoral rocky bottoms of the Avilés Canyon System (Cantabrian Sea). Front. Mar. Sci. Conf. Abstr. XX Iber. Symp. Mar. Biol. Stud. (SIEBM XX) 2019. [CrossRef]

3. Ríos, P.; Aguilar, R.; Torriente, A.; Muñoz, A.; Cristobo, J. Sponge grounds of Artemisina (Porifera, Demospongiae) in the Iberian Peninsula, ecological characterization by ROV techniques. Zootaxa 2018, 4466, 95-123. [CrossRef] [PubMed] 
4. Sánchez, F.; Serrano, A.; Ballesteros, M.G. Photogrammetric quantitative study of habitat and benthic communities of deep Cantabrian Sea hard grounds. Cont. Shelf Res. 2009, 29, 1174-1188. [CrossRef]

5. Ross, R.E.; Howell, K.L. Use of predictive habitat modelling to assess the distribution and extent of the current protection of 'listed' deep-sea habitats. Divers. Distrib. 2013, 19, 433-445. [CrossRef]

6. González-Mirelis, G.; Buhl-mortensen, P. Modelling benthic habitats and biotopes off the coast of Norway to support spatial management Ecological Informatics Modelling benthic habitats and biotopes off the coast of Norway to support spatial management. Ecol. Inform. 2015, 30, 284-292. [CrossRef]

7. Sánchez, F.; Rodríguez-Basalo, A.; García-Alegre, A.; Gómez-Ballesteros, M. Hard-bottom bathyal habitats and keystone epibenthic species on Le Danois Bank (Cantabrian Sea). J. Sea Res. 2017, 130, 134-135. [CrossRef]

8. Galparsoro, I.; Borja, Á.; Kostylev, V.E.; Rodríguez, J.G.; Pascual, M.; Muxika, I. Estuarine Coastal and Shelf Science A process-driven sedimentary habitat modelling approach, explaining sea floor integrity and biodiversity assessment within the European Marine Strategy Framework Directive. Estuar. Coast. Shelf Sci. 2013, 131, 194-205. [CrossRef]

9. Zapata-Ramírez, P.A.; Huete-stauffer, C.; Scaradozzi, D.; Marconi, M.; Cerrano, C. Testing methods to support management decisions in coralligenous and cave environments. A case study at Porto Fino MPA. Mar. Environ. Res. 2016, 118, 45-56. [CrossRef]

10. Buhl-Mortensen, L.; Buhl-Mortensen, P.; Dolan, M.J.F.; Gonzalez-Mirelis, G. Habitat mapping as a tool for conservation and sustainable use of marine resources: Some perspectives from the MAREANO Programme, Norway. J. Sea Res. 2015, 100, 46-61. [CrossRef]

11. Fulton, E.; Bax, N.; Bustamante, R.; Dambacher, J.; Dichmont, C.; Dunstan, P.; Hayes, K.; Hobday, A.; Pitcher, C.; Plaganyi, E.; et al. Modelling marine protected areas: Insights and hurdles. Biol. Sci. 2015, 370, 20140278370. [CrossRef]

12. Rodríguez-Basalo, A.; Sánchez, F.; Punzón, A.; Gómez-Ballesteros, M. Updating the Master Management Plan for El Cachucho MPA (Cantabrian Sea) using a spatial planning approach. Cont. Shelf Res. 2019, 184, 54-65. [CrossRef]

13. Brown, C.J.; Smith, S.J.; Lawton, P.; Anderson, J.T. Estuarine, Coastal and Shelf Science Benthic habitat mapping: A review of progress towards improved understanding of the spatial ecology of the sea floor using acoustic techniques. Estuar. Coast. Shelf Sci. 2011, 92, 502-520. [CrossRef]

14. Rowden, A.A.; Anderson, O.F.; Georgian, S.E.; Bowden, D.A.; Clark, M.R.; Pallentin, A.; Miller, A. High-Resolution Habitat Suitability Models for the Conservation and Management of Vulnerable Marine Ecosystems on the Louisville Seamount Chain, South Pacific Ocean. Front. Mar. Sci. 2017, 4, 335. [CrossRef]

15. Guinotte, J.; Baco, A.; Black, J.; Hall-spencer, J.M. Global habitat suitability of cold-water octocorals. J. Biogeogr. 2012, 39, 1278-1292. [CrossRef]

16. Lecours, V.; Devillers, R.; Schneider, D.C. Spatial scale and geographic context in benthic habitat mapping: Review and future directions. Mar. Ecol. Prog. Ser. 2015, 535, 259-284. [CrossRef]

17. Greene, H.G.; Yoklavich, M.M.; Starr, R.M.; O'Connell, V.M.; Wakefield, W.W.; Sullivan, D.E.; McRea, J.E., Jr.; Cailliet, G.M. A classification scheme for deep seafloor habitats. Oceanol. Acta 1999, 22, 663-678. [CrossRef]

18. Katya, K.; Sidinei, T.; Danielle, W. Habitat complexity: Approaches and future directions Habitat complexity: Approaches and future directions. Hydrobiologia 2012, 685. [CrossRef]

19. Lingo, M.E.; Szedlmayer, S.T. The Influence of Habitat Complexity on Reef Fish Communities in the Northeastern Gulf of Mexico. Environ. Biol. Fishes 2006, 76, 71-80. [CrossRef]

20. Moore, E.C.; Hovel, K.A. Relative influence of habitat complexity and proximity to patch edges on seagrass epifaunal communities. Oikos 2010, 119, 1299-1311. [CrossRef]

21. Rees, M.J.; Knot, N.A.; Neilson, J.M.; Linklater, M.; Osterloh, I.; Jordan, A.; Davis, A.R. Accounting for habitat structural complexity improves the assessment of performance in no-take marine reserves. Biol. Conserv. 2018, 224, 100-110. [CrossRef]

22. Gerovasileiou, V.; Chintiroglou, C.C.; Konstantinou, D. Sponges as 'living hotels' in Mediterranean marine caves. Sci. Mar. 2016, 80. [CrossRef]

23. Kalacska, M.; Chmura, G.L.; Lucanus, O.; Bérubé, D.; Arroyo-Mora, J.P. Structure from motion will revolutionize analyses of tidal wetland landscapes. Remote Sens. Environ. 2017, 199, 14-24. [CrossRef]

24. Palma, M.; Rivas-Casado, M.; Pantaleo, U.; Pavoni, G.; Pica, D.; Cerrano, C. SfM-Based Method to Assess Gorgonian Forests (Paramuricea clavata (Cnidaria, Octocorallia)). Remote Sens. 2018, 10, 1154. [CrossRef] 
25. Prado, E.; Sánchez, F.; Rodríguez-Basalo, A.; Altuna, Á.; Cobo, A. Analysis of the population structure of a gorgonian forest (Placogorgia sp.) using a photogrammetric 3D modeling approach at Le Danois Bank, Cantabrian Sea. Deep. Res. Part I Oceanogr. Res. Pap. 2019, 153. [CrossRef]

26. Prado, E.; Sánchez, F.; Rodríguez-Basalo, A.; Altuna, Á.; Cobo, A. Semi-Automatic Method of Fan Surface Assessment to Achieve Gorgonian Population Structure in Le Danois Bank, Cantabrian Sea. ISPRS Int. Arch. Photogramm. Remote. Sens. Spat. Inf. Sci. 2019, XLII-2/W10, 2-3. [CrossRef]

27. Bennecke, S.; Kwasnitschka, T.; Metaxas, A.; Dullo, W.C. In situ growth rates of deep-water octocorals determined from 3D photogrammetric reconstructions. Coral Reefs 2016, 35, 1227-1239. [CrossRef]

28. Olinger, L.K.; Scott, A.R.; Mcmurray, S.E.; Pawlik, J.R. Growth estimates of Caribbean reef sponges on a shipwreck using 3D photogrammetry. Sci. Rep. 2019, 9, 18398. [CrossRef]

29. Leon, J.X.; Roelfsema, C.M.; Saunders, M.I.; Phinn, S.R. Measuring coral reef terrain roughness using 'Structure-from-Motion' close-range photogrammetry. Geomorphology 2015, 242, 21-28. [CrossRef]

30. Young, G.C.; Dey, S.; Rogers, A.D.; Exton, D. Correction: Cost and time-effective method for multi-scale measures of rugosity, fractal dimension, and vector dispersion from coral reef 3D models. PLoS ONE 2018, 13, e0201847. [CrossRef]

31. He, H.; Ferrari, R.; McKinnon, D.; Roff, G.; Smith, R.; Mumby, P.; Upcroft, B.H. Measuring Reef Complexity and Rugosity from Monocular Video Bathymetric Measuring reef complexity and rugosity from monocular video bathymetric reconstruction. In Proceedings of the 12th International Coral Reef Symposium, Cairns, Australia, 9-13 July 2012; pp. 1-5.

32. Ferrari, R.; McKinnon, D.; He, H.; Smith, R.N.; Corke, P.; González-Rivero, M.; Mumby, P.J.; Upcroft, B. Quantifying multiscale habitat structural complexity: A cost-effective framework for underwater 3D modelling. Remote Sens. 2016, 8, 113. [CrossRef]

33. Price, D.M.; Robert, K.; Callaway, A.; lacono, C.L.; Hall, R.A.; Huvenne, V.A.I. Using 3D photogrammetry from ROV video to quantify cold- water coral reef structural complexity and investigate its influence on biodiversity and community assemblage. Coral Reefs 2019, 38, 1007-1021. [CrossRef]

34. Yanovski, R.; Nelson, P.A.; Abelson, A. Structural Complexity in Coral Reefs: Examination of a Novel Evaluation Tool on Different Spatial Scales. Front. Ecol. Evol. 2017, 5, 1-9. [CrossRef]

35. Robert, K.; Huvenne, V.A.I.; Georgiopoulou, A.; Jones, D.O.B.; Marsh, L.; Carter, G.D.O.; Chaumillon, L. New approaches to high-resolution mapping of marine vertical structures. Sci. Rep. 2017, 7, 1-14. [CrossRef] [PubMed]

36. Gerdes, K.; Arbizu, P.M.; Schwarz-schampera, U. Detailed Mapping of Hydrothermal Vent Fauna: A 3D Reconstruction Approach Based on Video Imagery. Front. Mar. Sci. 2019, 6. [CrossRef]

37. Hernández, P.; Graham, C.H.; Master, L.L.; Albert, D.L. The effect of sample size and species characteristics on performance of different species distribution modeling methods. Ecography 2006, 29, 773-785. [CrossRef]

38. Wisz, M.S.; Hijmans, R.J.; Li, J.; Peterson, A.T.; Graham, C.H.; Guisan, A. Effects of sample size on the performance of species distribution models. Diversity Distrib. 2008, 14, 763-773. [CrossRef]

39. Van Proosdij, A.S.J.; Sosef, M.S.M.; Wieringa, J.J.; Raes, N. Minimum required number of specimen records to develop accurate species distribution models. Ecography 2016, 39, 542-552. [CrossRef]

40. Beijbom, O.; Edmunds, P.J.; Kline, D.I.; Greg, M.B.; Kriegman, D. Automated Annotation of Coral Reef Survey Images Automated Annotation of Coral Reef Survey Images. In Proceedings of the IEEE Conference on Computer Vision and Pattern Recognition, Providence, RI, USA, 16-21 June 2012; pp. 1170-1177. [CrossRef]

41. Raghu, M.; Schmidt, E. A Survey of Deep Learning for Scientific Discovery. arXiv 2020, arXiv:2003.11755.

42. Moniruzzaman, M.; Islam, S.M.S.; Bennamoun, M.; Lavery, P. Deep learning on underwater marine object detection: A survey. In Proceedings of the International Conference on Advanced Concepts for Intelligent Vision Systems (ACIVS), Poitiers, France, 24-27 September 2017; Springer: Cham, Switzerland, 2017; 10617 LNCS, pp. 150-160. [CrossRef]

43. Mahmood, A.; Bennamoun, M.; An, S.; Sohel, F.; Boussaid, F.; Hovey, R.; Kendrick, G.; Fisher, R.B. Automatic annotation of coral reefs using deep learning. In Proceedings of the OCEANS 2016 MTS/IEEE Monterey, Monterey, CA, USA, 19-23 September 2016; pp. 1-5. [CrossRef]

44. Purser, A.; Bergmann, M.; Lundälv, T.; Ontrup, J. Use of machine-learning algorithms for the automated detection of cold-water coral habitats: A pilot study. Mar. Ecol. Prog. Ser. 2009, 397, 241-251. [CrossRef] 
45. Beijbom, O.; Edmunds, P.J.; Roelfsema, C.; Smith, J.; Kline, D.I.; Neal, B.P.; Dunlap, M.J.; Moriarty, V.; Fan, T.-Y.; Tan, C.-J. Towards Automated Annotation of Benthic Survey Images: Variability of Human Experts and Operational Modes of Automation. PLoS ONE 2015, 10. [CrossRef]

46. Pavoni, G.; Corsini, M.; Callieri, M.; Palma, M.; Scopigno, R. Semantic segmentation of benthic communities from ortho-mosaic maps. Int. Arch. Photogramm. Remote Sens. Spatial Inf. Sci. 2019, XLII-2/W10, 151-158. [CrossRef]

47. Hopkinson, B.M.; King, A.C.; Owen, D.P.; Johnson-Roberson, M.; Long, M.H.; Bhandarkar, S.M. Automated classification of three-dimensional reconstructions of coral reefs using convolutional neural networks. PLOS ONE 2020, 15, e0230671. [CrossRef]

48. Mohamed, H.; Nadaoka, K.; Nakamura, T. Towards Benthic Habitat 3D Mapping Using Machine Learning Algorithms and Structures from Motion Photogrammetry. Remote Sens. 2020, 12, 127. [CrossRef]

49. Punzón, A.; Arronte, J.C.; Sánchez, F.; García-alegre, A. Spatial characterization of the fisheries in the Avilés Canyon System (Cantabrian Sea, Spain) Caracterización espacial de las pesquerías en el Sistema de Cañones de Avilés (mar Cantábrico, España). Cienc. Mar. 2016, 42, 237-260. [CrossRef]

50. Ercilla, G.; Casas, D.; Estrada, F.; Vázquez, J.T.; Iglesias, J.; García, M. Morphosedimentary features and recent depositional architectural model of the Cantabrian continental margin. Mar. Geol. 2008, 247, 61-83. [CrossRef]

51. Gómez-Ballesteros, M.; Druet, M.; Muñoz, A.; Arrese, B.; Rivera, J.; Sánchez, F.; Cristobo, J.; Parra, S.; García-Alegre, A.; González-Pola, C.; et al. Geomorphology of the Avilés Canyon System, Cantabrian Sea (Bay of Biscay). Deep. Res. Part II 2014, 106, 99-117. [CrossRef]

52. Sánchez, F.; González-Pola, C.; Druet, M.; García-Alegre, A.; Acosta, J.; Cristobo, J.; Parra, S.; Ríos, P.; Altuna, Á.; Gómez-Ballesteros, M.; et al. Habitat characterization of deep-water coral reefs in La Gaviera Canyon (Avilés Canyon System, Cantabrian Sea). Deep. Res. Part II 2014, 106, 118-140. [CrossRef]

53. Sánchez, F.; Rodríguez, J.M. POLITOLANA, a new low cost towed vehicle designed for the characterization of the deep-sea floor. In Proceedings of the Martech 2013 5th International Workshop on Marine Technology, Girona, Spain, 9-11 October 2013.

54. Huetten, E.; Greinert, J. Software controlled guidance, recording and post-processing of seafloor observations by ROV and other towed devices: The software package OFOP. Geophys. Res. Abstr. 2008, 10; SRef-ID: 1607-7962/gra/EGU2008-A-03088.

55. Tola, E.; Lepetit, V.; Fua, P.; Member, S. DAISY: An Efficient Dense Descriptor Applied to Wide-Baseline Stereo. IEEE Trans. Softw. Eng. 2010, 32, 815-830. [CrossRef] [PubMed]

56. Haase, P. Spatial pattern analysis in ecology based on Ripley's K-function: Introduction and methods of edge correction. J. Veg. Sci. 1995, 6, 575-582. [CrossRef]

57. Bochkovskiy, A.; Wang, C.-Y.; Liao, H.-Y.M. YOLOv4: Optimal Speed and Accuracy of Object Detection. arXiv 2020, arXiv:2004.10934. Available online: Arxiv.org/abs/2004.10934 (accessed on 11 June 2020).

58. Anderson, O.F.; Guinotte, J.M.; Rowden, A.A.; Clark, M.R.; Mormede, S.; Davies, A.J.; Bowden, D.A. Field validation of habitat suitability models for vulnerable marine ecosystems in the South Pacific Ocean: Implications for the use of broad-scale models in fisheries management. Ocean Coast. Manag. 2016, 120, 110-126. [CrossRef]

59. Storlazzi, C.D.; Dartnell, P.; Hatcher, G.A.; Gibbs, A.E. End of the chain? Rugosity and fine-scale bathymetry from existing underwater digital imagery using structure-from-motion (SfM) technology. Coral Reefs 2016, 35, 887-892. [CrossRef]

60. Jackson, T.D.U.; Williams, G.J.; Walker-Springett, G.; Davies, A.J. Three-dimensional digital mapping of ecosystems: A new era in spatial ecology. Proc. R. Soc. B. 2020, 287, 20192383. [CrossRef] [PubMed]

61. Dumas, P.; Jimenez, H.; Peignon, C.; Wantiez, L.; Adjeroud, M. Small-Scale Habitat Structure Modulates the Effects of No-Take Marine Reserves for Coral Reef Macroinvertebrates. PLoS ONE 2013, 8. [CrossRef] [PubMed]

62. Figueira, W.; Ferrari, R.; Weatherby, E.; Porter, A.; Hawes, S.; Byrne, M. Accuracy and precision of habitat structural complexity metrics derived from underwater photogrammetry. Remote Sens. 2015, 7, 16883-16900. [CrossRef]

63. Burns, J.H.R.; Fukunaga, A.; Pascoe, K.H.; Runyan, A.; Craig, B.K.; Talbot, J.; Pugh, A.; Kosaki, R.K. 3D Habitat Complexity of Coral Reefs in the Northwestern Hawaiian Islands is Driven by Coral Assemblage Structure. Int. Arch. Photogramm. Remote Sens. Spatial Inf. Sci. 2019, XLII-2/W10, 61-67. [CrossRef] 
64. Fukunaga, A.; Burns, J.H.R.; Pascoe, K.H.; Kosaki, R.K. Associations between Benthic Cover and Habitat Complexity Metrics Obtained from 3D Reconstruction of Coral Reefs at Different Resolutions. Remote Sens. 2020, 12, 1011. [CrossRef]

65. Broom, D.M. Aggregation behaviour of the brittle-star ophiothrix fragilis. J. Mar. Biol. Assoc. UK 1975, 55, 191-197. [CrossRef]

66. Altuna, A.; Poliseno, A. 14 Taxonomy, Genetics and Biodiversity of Mediterranean Deep-Sea Corals and Cold-Water Corals. In Mediterranean Cold-Water Corals: Past, Present and Future. Coral Reefs of the World; Orejas, C., Jiménez, C., Eds.; Springer: Cham, Switzerland, 2019; Volume 9, pp. 531-533. [CrossRef]

(C) 2020 by the authors. Licensee MDPI, Basel, Switzerland. This article is an open access article distributed under the terms and conditions of the Creative Commons Attribution (CC BY) license (http://creativecommons.org/licenses/by/4.0/). 